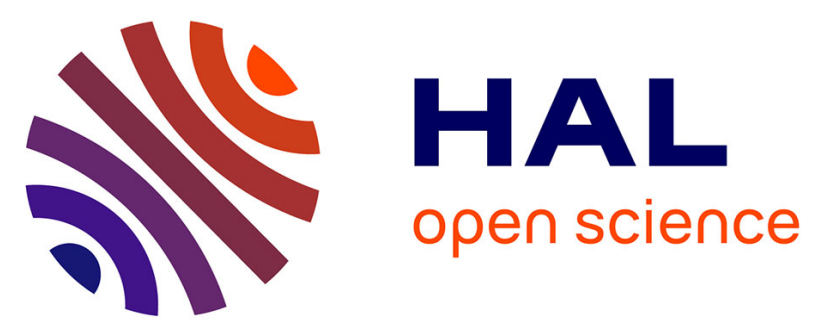

\title{
Phytomanagement of a metal(loid)-contaminated agricultural site using aromatic and medicinal plants to produce essential oils: analysis of the metal(loid) fate in the value chain.
}

Alexandre Perlein, Isabelle Zdanevitch, Rodolphe Gaucher, Brett Robinson, Arnaud Papin, Anissa Lounes-Hadj Sahraoui, Valérie Bert

\section{To cite this version:}

Alexandre Perlein, Isabelle Zdanevitch, Rodolphe Gaucher, Brett Robinson, Arnaud Papin, et al.. Phytomanagement of a metal(loid)-contaminated agricultural site using aromatic and medicinal plants to produce essential oils: analysis of the metal(loid) fate in the value chain.. Environmental Science and Pollution Research, 2021, 10.1007/s11356-021-15045-4 . ineris-03310658

HAL Id: ineris-03310658

https://hal-ineris.archives-ouvertes.fr/ineris-03310658

Submitted on 19 Oct 2021

HAL is a multi-disciplinary open access archive for the deposit and dissemination of scientific research documents, whether they are published or not. The documents may come from teaching and research institutions in France or abroad, or from public or private research centers.
L'archive ouverte pluridisciplinaire HAL, est destinée au dépôt et à la diffusion de documents scientifiques de niveau recherche, publiés ou non, émanant des établissements d'enseignement et de recherche français ou étrangers, des laboratoires publics ou privés. 
Title: Phytomanagement of a metal(loid)-contaminated agricultural site using aromatic and medicinal plants to produce essential oils: analysis of the metal(loid) fate in the value chain.

Alexandre PERLEIN ${ }^{\mathrm{a}, \mathrm{b}}$, Isabelle ZDANEVITCH ${ }^{\mathrm{a}}$, Rodolphe GAUCHER ${ }^{\mathrm{a}}$, Brett ROBINSON ${ }^{\mathrm{c}}$, Arnaud PAPIN $^{\mathrm{d}}$, Anissa LOUNES-HADJ SAHRAOUI ${ }^{\mathrm{e}}$, Valérie BERT ${ }^{\mathrm{a}^{*}}$

a Unité Technologies Propres et Economie Circulaire, INERIS, Parc Technologique Alata, BP2, 60550 Verneuilen-Halatte, France

${ }^{\mathrm{b}}$ Department of Green Chemistry and Technology, Ghent University, Ghent, Belgium

${ }^{c}$ School of Physical and Chemical Sciences, University of Canterbury, Christchurch 8041, New Zealand

d Analytical methods and developments for the environment, INERIS, Parc Technologique Alata BP 2, 60550

Verneuil en Halatte, France

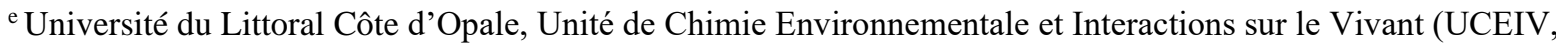
UR 4492), SFR Condorcet FR CNRS 3417, 50 rue Ferdinand Buisson, 62228 Calais cedex, France

*Corresponding author: valerie.bert@ineris.fr, +33 344556382

\begin{abstract}
Phytomanagement uses plants and soil conditioners to create value on contaminated land while minimising environmental risk. This work was carried out on a metal(loid)-contaminated site and aimed at assessing the suitability of Salvia sclarea L. (sage) and Coriandrum sativum L. (coriander) combined with an Arbuscular Mycorrhizal Fungus (AMF) inoculant to immobilise metal(loid)s and produce essential oils (EO). The effect of the inoculant on the transfer of metal(loid)s (ML, i.e. $\mathrm{Cd}, \mathrm{Cu}, \mathrm{Pb}, \mathrm{Zn}, \mathrm{As}, \mathrm{Ni}$, and $\mathrm{Sb}$ ) to plants and the ML soil mobility were investigated. The ML concentrations in EO from both plant species and the valorisation options for the distillation residues (soil conditioner, animal fodder, and anaerobic digestion) were studied. Sage was a suitable candidate for this value chain because it presents an excluder phenotype and the residues of oil extraction could be used as a soil conditioner. The metal concentrations in the sage EO were similar to those obtained from plants cultivated on an uncontaminated soil. These results indicate the suitability of sage harvested on the contaminated soil according to the ML fate in the whole value chain. Like the EO of sage, ML concentrations in the coriander
\end{abstract}


EO did not differ from those in the commercial EO that were obtained from plants grown on uncontaminated soil. However, the use of distillation residues of coriander was limited by their relatively elevated Cd concentrations. The use of a mycorrhizal inoculum did not decrease the Cd mobility in soil for the coriander.

Keywords Salvia sclarea, Coriandrum sativum, Cadmium, Arbuscular mycorrhizal fungi, Aided phytostabilisation, Biomass valorisation, Distillation residues 
Ethics approval and consent to participate Not applicable.

Consent for publication Not applicable.

Availability of data and materials Not applicable.

Competing interests The authors declare that they have no competing interests.

Funding information This work was supported by national public funds through PhyTEO (ADEME - Agence De la Transition Ecologique, convention n 1772C0020, 2017-2020).

Authors' contributions This collaboration work was carried out among all the authors. AP designed outlines and wrote the draft, performed the statistical analyses and prepared the figures and the tables of the manuscript. VB proposed original idea, wrote some part of the manuscript and reviewed the scientific contents of the manuscript. IZ wrote some part of the manuscript and reviewed the manuscript. RG reviewed the manuscript. AP was responsible for the validation of the data quality obtained by ICP and wrote some part of the manuscript. BR reviewed the manuscript and improve the text quality. AL was responsible for the funding acquisition (PhyTEO), coordinated the project and reviewed the manuscript.

Acknowledgments The authors thank Fabrice Richez, Yohann Baillon, Samuel Teillaud, Robin Raveau and Joël Fontaine for their technical contribution during the sampling campaigns and/or chemical analysis and fruitful discussions. Commercial EO of coriander and sage were kindly provided by Ferrand PHE. Ferrand PHE is also thanked for the production and the providing of non-commercial EOs used in this work. We thank the anonymous reviewers for their comments, which greatly helped us to improve the manuscript. 


\section{1) Introduction}

Soil contamination is a worldwide concern. In Europe, industrial and commercial activities have contaminated 342,000 sites to the extent that they pose a potential risk for human health and the environment (van Liedekerke et al. 2014). Among these sites, one third were contaminated by metal(loid)s (ML), which cause persistent degradation of soil quality. To manage the risk due to ML contamination, civil engineering remediation techniques such as excavation are used to remove the contaminated soil. Although these techniques are efficient in removing the contamination from the site, they are prohibitively expensive over large areas. They also produce waste that needs to be managed and they often destroy local ecosystems (Ali et al. 2013; Cundy et al. 2016; Hooper et al. 2015). In contrast, plant-based technologies (phytotechnologies) may represent a low-cost and long-term approach to improving contaminated soil. Ideally suited to large areas of contamination, the aim of these phytotechnologies is to manage environmental risk and exposure by decreasing pollutant transfers in the environment (phytostabilisation) or by the partial removal of pollutants in the soil (phytoextraction or bioavailable contaminant stripping) (Kidd et al. 2015; Robinson et al. 2015). Phytomanagement aims to generate financial returns from contaminated land via the introduction of biomass into a sustainable value chain (Robinson et al. 2009; Evangelou and Deram, 2014; Burges et al. 2018). Since 2010, much research has focused on the conversion of biomass into bioenergy and raw materials. Biomass could be valorised through combustion, pyrolysis, gasification, anaerobic digestion (Delplanque et al. 2013; Chalot et al. 2012; Bert et al. 2017; Meers et al. 2010) or prepared to obtain high value products such as platform-chemicals, fibers and ecomaterials (e.g. Deyris et al. 2018; Ziegler-Devin et al. 2019; Jeannin et al. 2020; Dias and Waldmann 2020).

Essential Oils (EOs) distilled from aromatic and medicinal plants (AMP) are used in foods, personal care products, cosmetics, aromatherapy sectors, and in products such as detergents, biological pesticides, soaps, concentrates, extracts, additives, etc. (Barbieri and Borsotto, 2018; Eikani et al. 2007; Jisha et al. 2017; El-Alam et al. 2020; Raveau et al. 2020). High-value EOs are traded worldwide and the market is expected to grow (Barbieri and Borsotto, 2018).

Few studies have reported the use of AMP grown on polluted soils to produce EOs (Zheljazkov et al. 2008; Angelova et al. 2016; Seyedalikhani et al. 2020). The soil-plant transfer of $\mathrm{Cd}, \mathrm{Pb}$ and $\mathrm{Cu}$ in polluted plots was low and the authors concluded that AMP such as Ocimum basilicum L. (basil), Mentha x piperita L. (peppermint), coriander and Salvia officinalis $\mathrm{L}$. did not accumulate $\mathrm{Cd}, \mathrm{Pb}$ and $\mathrm{Cu}$ in aerial parts and that the hydrodistillation 
of basil, peppermint and sage led to a limited transfer of $\mathrm{Cu}, \mathrm{Cd}$ and $\mathrm{Pb}$ in $\mathrm{EO}$, which suggested that these $\mathrm{EO}$ could be marketed (Zheljazkov et al,. 2008; Seyedalikhani et al. 2019).

Two review papers proposed using AMP in a phytomanagement context based on their composition leading to EO and their tolerance to ML in soil (Jisha et al. 2017; Ait Elallem et al. 2020). They suggested integrating distillation residues for bioenergy production. To our knowledge, amongst AMP, only a few were studied in this context. For instance, Angelova et al. (2016) performed in situ experiments with sage according to different levels of ML pollution and found no signs of toxicity up to 3000 and $60 \mathrm{mg} \mathrm{kg}^{-1}$ foliar $\mathrm{Zn}$ and $\mathrm{Cd}$ concentrations, respectively. Mycorrhizal inoculation improves the ML stress tolerance of plants and decreases the ML transfer in aerial plant parts and participates in the reduction of the ML mobility in soil by different mechanisms (Leung et al. 2013; Phanthavongsa et al. 2017). Mycorrhizal inoculation of coriander in a pot experiment with a $\mathrm{Pb}$ salt showed a reduction of toxicity signs and foliar $\mathrm{Pb}$ concentration at $1500 \mathrm{mg} \mathrm{Pb} \mathrm{kg}^{-1}$ in the soil (Fatemi et al. 2020). In contrast, the mycorrhizal inoculation of sage increased the shoot $\mathrm{Cd}$ and $\mathrm{Pb}$ concentrations and the authors reported the limited tolerance of the arbuscular mycorrhizal fungi (AMF) to $\mathrm{Cd}$ and $\mathrm{Pb}$ (Nowak, 2007).

Amongst the AMP, many produce a high aerial biomass of which only a part is used for EO production. The residues of distillation as well as the remaining plant parts could be integrated to the value chain if they are beneficially reused. On uncontaminated soil, biomass residues are commonly used as animal fodder, composts and for energy production (Jisha et al. 2017). To our knowledge, on polluted soils, the feasibility of such an overall value chain, i.e. including the production of $\mathrm{EO}$ and the valorisation of the distillation residues, based on the ML fate has not been studied.

This work aimed to determine the feasibility of phytomanaging a metal-contaminated site using sage and coriander to produce EOs. Both plant species are considered as relevant candidates in this value chain (Zheljazkov et al. 2008; Angelova et al. 2016; Cui et al. 2015; Mandal and Mandal, 2015; Matasyoh et al. 2009). A second aim was to assess the effect of an AMF inoculant on (i) the ML transfer to aerial plant parts and (ii) the solubility of the ML in soil. Other specific objectives were to investigate the EO quality obtained from both plant species regarding ML and the valorisation options for the distillation residues (soil improver, animal fodder and anaerobic digestion). This study was carried out in the frame of the PhytEO project in which other plant parameters such as plant growth, development and biomass production, as well as the techno-economic feasibility of the phytomanagement strategy were studied (Raveau, 2020). 


\section{2) Materials and Methods}

\section{1) Site description and experimental design}

Experiments were performed in the north of France on an agricultural area (Evin-Malmaison; 1.3 ha; 50 $25^{\prime} 55.5^{\prime}$, $\mathrm{N}, 3^{\circ} 02^{\prime} 25.5^{\prime}$ ' E, Fig.1) contaminated by past industrial emissions of a $\mathrm{Pb} / \mathrm{Zn}$ smelter that led to ML contamination of the topsoil with, notably, $\mathrm{Cd}, \mathrm{Pb}, \mathrm{Cu}$ and $\mathrm{Zn}$ (Sterckeman et al. 2002). Two AMP species, the biennial clary sage (Salvia sclarea L.) and the annual coriander (Coriandrum sativum L.), were cultivated on the contaminated site. Half of the site was devoted to sage whereas the other part was devoted to coriander. Each half was further divided according to inoculation carried out with a commercial AMF inoculant (Rhizophagus irregularis; 12000 viable spores per gram of product; AGTIV® Specialty Crops; PremierTech). After soil preparation realized with conventional tillage ( $0.1 \mathrm{~m}$-depth ploughing), the powdery inoculant was introduced during sowing of certified sage and coriander seeds (https://www.iteipmai.fr/) at a rate of $125 \mathrm{~g} \mathrm{ha}^{-1}$. This division led to inoculated (I, $\left.2000 \mathrm{~m}^{2}\right)$ and non-inoculated (NI, 4000m²) plots. Sowing occurred in April 2017 for both species (300 000 seeds per hectare, 3-4 cm depth). The annual coriander was resown in April 2018 for a second crop.

A similar experimental design was set up on an uncontaminated soil (1.4 ha $\left.-50^{\circ} 49^{\prime} 55.7^{\prime \prime} \mathrm{N}, 1^{\circ} 55^{\prime} 46.9^{\prime \prime} \mathrm{E}\right)$. This site was used as a reference for comparing the metal-concentrations in the plant parts (see section 2.3). Plants were processed the same as those from the contaminated site. We report the concentrations obtained in the EO and the distillation residues from this site for comparison with those obtained from the contaminated site (see sections 2.4 and 2.5).

\section{2) Soil sampling and agro-physicochemical analyses}

In April 2017, soil sample composites were made from 19 top-soil samples randomly collected with a hand auger on the whole site (Table 1). The soil physicochemical properties measured on these samples are presented in Table 2 and reported as initial state (IS) data in the further text.

Once the plots were designed, soil samples were taken before sowing and harvesting. In July and September 2017 , 12 samples were taken from the inoculated plots (I) and 18 samples were taken from the non-inoculated ones (NI). After geo-localisation, all top-soil samples (0-20 cm depth) were dried at $40^{\circ} \mathrm{C}$ in a forced air oven to a constant weight, ground with a grinder (agate mortar, Retsch BB51) and sieved to $<2 \mathrm{~mm}$ (Retsch AS 200 digit). Soil pH was measured following the NF ISO 10390 (2005) standard. Five g of $2 \mathrm{~mm}$ sieved soils were mixed with $25 \mathrm{~mL}$ of distilled water and shaken for 2 hours. Water $\mathrm{pH}$ was measured after a $1 \mathrm{~h}$ rest. Total concentrations of $\mathrm{ML}$ 
were analysed in the soil samples collected in July and September 2017 and digested (Mars Xpress CEM) following the NF-EN-13656. Briefly, $0.5 \mathrm{~g}$ soil were digested at $180{ }^{\circ} \mathrm{C}$ for $20 \mathrm{~min}$ with $2 \mathrm{~mL}$ of nitric acid $\left(\mathrm{HNO}_{3}\right.$ 67\%), $6 \mathrm{~mL}$ of hydrochloric acid ( $\mathrm{HCl} 36 \%)$ and $2 \mathrm{~mL}$ of hydrofluoric acid (HF 48\%) and filtered using $0.45 \mu \mathrm{m}$

Whatman ${ }^{\circledR}$ filter paper. To estimate the easily soluble fraction (water-soluble compounds, exchangeable ions, and readily soluble metal complexes) of ML in these soils, a selective extraction was performed with $1 \mathrm{M}$ ammonium nitrate $\left(\mathrm{NH}_{4} \mathrm{NO}_{3}\right)$ solution following the NF ISO 19730:2008(E).

After $2 \mathrm{~h}$ shaking on an agitation table, the soil-extractant mixtures were passed through a Millipore filter $(\varnothing$ $0.45 \mu \mathrm{m})$ and leachates acidified to a $\mathrm{pH}$ of 2 and stored for analysis. The ML concentrations in the eluates and solutions were analysed either by ICP-OES (Agilent 700, Agilent 5100) or ICP-MS (Agilent 7500) depending on sample concentrations. Recoveries are presented in supplemental table 1. As no upper critical threshold ML concentrations exist in France to define a contaminated soil (as it is a site-specific risk assessment accounting for soil series and land use), all total soil ML (Table 2) were compared to background ML concentrations in French soils (Baize, 2000). The total topsoil $\mathrm{Cd}, \mathrm{Cu}, \mathrm{Pb}$ and $\mathrm{Zn}$ were all above the highest values $(0.45,20,50$ and 100 $\mu \mathrm{g} \mathrm{g}^{-1}$ dry soil (DS), respectively), thereby indicating soil ML contamination. Due to their inordinately high concentrations and their mobility (Denaix et al. 2001), the results section of this paper focuses on $\mathrm{Cd}, \mathrm{Cu}, \mathrm{Pb}$ and $\mathrm{Zn}$.

\section{3) Plant sampling and metal(loid) analyses}

The plant sampling strategy occurred in accordance with the soil sampling strategy (Table 1), i.e. 12 and 18 plant samples were collected for the I and the NI plots, respectively. For both, the harvest was different according to the species and the plant stage (Table 1). Samples of sage inflorescence were either washed or unwashed to determine the effect of washing on inflorescence ML concentration (Table 1). Plant washing could be important if soil dust containing ML are deposited on aerial plant parts (Hibben et al. 1984). In case of washing, plant materials were carefully washed with tap and deionised water before drying at $40{ }^{\circ} \mathrm{C}$ until constant weight. ML were analyzed in all plant samples $(0.5 \mathrm{~g})$ after digestion at $180{ }^{\circ} \mathrm{C}$ for $20 \mathrm{~min}$ in $10 \mathrm{~mL}$ of nitric acid $\left(\mathrm{HNO}_{3} 69 \%\right.$ AnalaR Normapur) and $3 \mathrm{~mL}$ of ultra-pure water using a microwave digester (Mars Xpress CEM) by ICP-OES (Agilent 5100) or ICPMS (Agilent 7500). To get ML-reference values, coriander and sage grown on the uncontaminated site (Table 2) were collected at the same stage and date and analysed as described above. Recovery rates for ML are presented in the supplemental table 1. 


\section{4) Essential oil sampling and metal(loid) analyses}

After harvest, the plant material from the I and NI plots were separately processed using water vapor $\left(80^{\circ} \mathrm{C}\right)$ to obtain the essential oils (EO). The distillation process was performed in the equipment of an EO industrial producer (Ferrand P.H.E., https://www.ferrantphe.com/production-de-concentres/ Rodelinghem, Hauts-de-France, France). EO samples $(5 \mathrm{~mL})$ obtained from each plant material were sent to INERIS for ML analysis. Each sample was divided in three sub-samples and digested following the plant procedure digestion described in \$2.3. ML concentrations in all EOs (0.5 g) were measured by ICP-OES (Agilent 5100) or ICP-MS (Agilent 7500). MLs in EO produced from coriander and sage grown on the uncontaminated site as well as commercial EO of both plant species were measured for comparison. Recovery rates for MLs are presented in the supplemental Table 1.

\section{5) Sampling of distillation residues and metal(loid) analyses}

The distillation process resulted in significant quantities of plant residues. Residue samples were oven-dried $\left(40^{\circ} \mathrm{C}\right.$, $48 \mathrm{~h}$ ) and homogenised after grinding to get a representative sample. Three sub-samples were selected to analyse the ML concentrations after digestion and analysis (as described in §2.3). MLs in plant residues produced from coriander and sage grown on the uncontaminated site were measured for comparison.

\section{6) Biomethane potential of distillation residues}

The measurement of the biomethane potential (BMP) of coriander and sage residues of the distillation performed in 2017 was subcontracted (https://www6.montpellier.inrae.fr/it-e, France). Briefly, the distillation residues as substrates and the microbial inoculum were put in a batch reactor for 23 days at $35^{\circ} \mathrm{C}$. The test was performed in duplicates. BMP was expressed in normal conditions of temperature and pressure $\left(0^{\circ} \mathrm{C}\right.$ and $\left.1013 \mathrm{hPa}\right)$.

\section{7) Statistical analysis}

The statistical analysis of the values and the boxplots were produced using R 3.5.2 (12/20/2018) and R studio. Before performing the variance homogeneity test (Bartlett test or Fligner-Killeen test), the normality of the data (Shappiro test) was checked. Means were compared by ANOVA when the data were parametric and by Kruskal- 
Wallis test when they were not. A post hoc test (Tukey HSD test or pairwise t test) was applied when a statistical difference at 5 percent risk was found. A Pearson correlation was used to determine correlation between variables.

\section{8 ) Calculations}

Bioconcentration factors (BCF) were calculated as follows:

$$
\begin{aligned}
& \text { BCF ext }=[\mathrm{ML}] \text { plant } /[\mathrm{ML}] \text { extractable soil } \\
& \text { BCF tot }=[\mathrm{ML}] \text { plant } /[\mathrm{ML}] \text { total soil }
\end{aligned}
$$

ML mobility was calculated as follows:

$$
\% \text { mobility }=[\mathrm{ML}] \text { extractable soil } /[\mathrm{ML}] \text { total soil } * 100
$$

In the calculations, $[\mathrm{ML}]$ means ML concentration; $[\mathrm{ML}]$ plant means ML concentration in either the shoots or the seeds, depending on the type of plant; [ML] extractable soil means $1 \mathrm{M} \mathrm{NH}_{4} \mathrm{NO}_{3}$-extractable soil ML; [ML] total soil means total soil ML.

\section{3) Results and Discussion}

\section{1) Mycorrhizal inoculation and plant effects on soil $p H$}

\subsection{1) Coriander}

The initial soil $\mathrm{pH}$ was alkaline $(7.86 \pm 0.13$; Table 2$)$. As coriander is an annual plant, it was cultivated twice leading to two sowing and two harvests. Fig. 2A presents the soil $\mathrm{pH}$ values from each harvest. At the end of the $1^{\text {srt }}$ harvest, the soil $\mathrm{pH}$ was similar to the initial sampling, indicating no plant effect. There was no statistical difference $(\mathrm{p}>0.05)$ between the I and NI plots, suggesting no inoculation effect. Before the new sowing, a significant soil $\mathrm{pH}$ increase was measured in the case of the I plot indicates an inoculation effect. When symbiosis is effective between the AMF and the root system, a significant reduction in acidity (an increase of one pH unit occurs due to $\mathrm{N}$ uptake. Root or hyphae $\mathrm{NO}_{3}{ }^{-}$uptake leads to a release of $\mathrm{OH}^{-}$which increases the $\mathrm{pH}(\mathrm{Bago}$ et al. 1996; Bago and Azcon-Aguilar 1997; Li and Christie 2001). However, this effect was small (0.5 pH unit) and did not last. Factors other than an inoculation effect, for example climatic conditions and the soil tillage, could explain this result. Bai et al. (2018) showed that the tillage had no long-term impact on $\mathrm{pH}$ which is consistent with our hypothesis. In contrast, the significant decrease of the soil $\mathrm{pH}$ measured for I and NI plots at the end of the second culture clearly showed a plant effect, as a result of cation uptake and root exudation of organic acids. Microbial respiration may also acidify the soil (Hinsinger et al. 2003). 


\subsection{2) Sage}

In contrast to coriander, sage is a biennial species. It was sown once and grown for two years. The $\mathrm{pH}$ was thus measured in the soil at two different stages of the plant development, i.e. Year 1 (leafy stage) and Year 2 (inflorescence stage) (Fig. 2B). A mycorrhizal inoculation effect leading to a significant increase in $\mathrm{pH}(0.2 \mathrm{pH}$ units) occurred during the $1^{\text {st }}$ year $(\mathrm{p}<0.05)$ that might result from soil microorganism respiration and root cations/anions uptake modification such as an uptake of $\mathrm{NO}_{3}{ }^{-}$(Hinsinger et al. 2003; Bago et al. 1996). The pH decreased during the second year in both I and NI plots may be attributed to differential root uptake of $\mathrm{NH}_{4}{ }^{+}$versus $\mathrm{NO}_{3}{ }^{-}$, the release of $\mathrm{OH}^{-} / \mathrm{H}^{+}$and the production of organic acids (Hinsinger et al. 2003).

\section{2) Mycorrhizal inoculation and plant effects on $\mathrm{NH}_{4} \mathrm{NO}_{3}$ extractable fraction in soil}

The extractable ML concentrations that are frequently encountered in soil are reported in the ISO 19730:2008 (E). These are: $\mathrm{Zn}\left(0.25 \mu \mathrm{g} \mathrm{g}^{-1}\right.$ dry soil), $\mathrm{Cd}\left(0.005 \mu \mathrm{g} \mathrm{g} \mathrm{g}^{-1}\right.$ dry soil), $\mathrm{Pb}\left(0.02 \mu \mathrm{g} \mathrm{g}^{-1}\right.$ dry soil $)$ and $\mathrm{Cu}\left(0.25 \mu \mathrm{g} \mathrm{g}^{-1}\right.$ dry soil). The $\left(1 \mathrm{M}-\mathrm{NH}_{4} \mathrm{NO}_{3}\right)$ extractable metal soil values are used as indicative values in this paper. There are no references for extractable ML in French soils and the extractable ML values of the uncontaminated soil could not be used as a reference for comparison with the contaminated one because it clearly showed different agrophysicochemical properties (Table 2). The mean values of the extractable ML concentrations for both the initial state (IS) of the soil, i.e. before the set-up of the experimental design (Table 2) and the soil once the plots were designed (Fig. 3, Fig. 4) were higher than the indicative values for $\mathrm{Zn}, \mathrm{Cd}, \mathrm{Pb}$ and $\mathrm{Cu}$ found in the ISO 19730:2008 (E) indicating that the extractable ML concentrations in the contaminated soil are higher than those frequently measured in soil. The ML mobility, which refers to the extractable ML concentration over the total ML concentration in soil, was ranked in the following order: $\mathrm{Cd}>\mathrm{Cu}=\mathrm{Sb}>>\mathrm{Zn}=\mathrm{Ni} \gg>\mathrm{Pb}=\mathrm{As}=\mathrm{Cr}$ (Supplemental Table 2), i.e. the $\mathrm{Cd}$ had the highest mobility whereas the $\mathrm{Pb}$ had the lowest.

\subsection{1) Coriander}

An increase in the extractable soil $\mathrm{Zn}$ was observed after one harvest in the I and NI plots compared to the IS value (Fig. 3; 2 and 4 times highest, respectively). This increase may be due to a plant effect and not to an inoculation 
effect $(p>0.05)$ as shown in Fig. 3A. The cultivation of the coriander for a second year showed neither an inoculation effect nor a plant effect $(\mathrm{p}>0.05)$ on the extractable soil Zn (Fig. 3A).

The $\mathrm{Zn}$ decrease between both cultures (Fig. 3A) could not be explained by the differences in the soil pH nor the extractable soil $\mathrm{Zn}(\mathrm{p}>0.05)$, whereas such a correlation would be expected; soil $\mathrm{pH}$ being pivotal for $\mathrm{Zn}$ solubility (Gartler et al. 2013). Other soil parameters such as the Cation Exchange Capacity (CEC) (Table 2) combined with the climatic conditions could explain this decrease (Kabata-Pendias 2011). Meite et al. (2018) showed that the alternation of drought (April to July 2017 and April to July 2018) and waterlogging (August 2017 to April 2018), which occurred before the first sowing of the coriander and during the coriander monitoring may have led to variations in the leaching of the water-soluble $\mathrm{Zn}$ and in extractable $\mathrm{Zn}$ concentrations.

At the end of the $2^{\text {nd }}$ culture before harvest, the extractable soil $\mathrm{Zn}$ did not differ from the IS mean (Fig. 3), i.e. before the experimental set up, showing that the addition of the inoculum combined with coriander did not reach the objective of aided phytostabilisation, i.e. a reduction of the initial extractable soil $\mathrm{Zn}$.

Over both cultures (Fig. 3B), the mean extractable soil Cd concentrations were similar to the IS value (Fig. 3). There was no effect of the inoculation or the crop during either culture $(\mathrm{p}>0.05)$. As a result, the extractable soil $\mathrm{Cd}$ was unchanged by the coriander and the inoculum.

No inoculation and no plant effects were shown on the extractable soil $\mathrm{Pb}$ and $\mathrm{Cu}$ (Fig. 3C and D). As with $\mathrm{Cd}$, the combination of the inoculum and coriander did not decrease these soil fractions. Moreover, the extractable soil fraction did not differ from the IS mean for both metals.

All the extractable soil fractions $(\mathrm{Zn}, \mathrm{Cd}, \mathrm{Pb}$, and $\mathrm{Cu})$ remained higher than the indicative values (from 22 to 28 times in the case of Cd) (Fig. 3).

The ML mobility calculated as the ratio of the extractable soil ML over the total soil ML agreed with the results on extractable soil ML (Supplemental Table 2). The ML mobility was similar to the initial hypothesis, namely $\mathrm{Cd}>\mathrm{Cu} \gg \mathrm{Zn} \gg \gg \mathrm{Pb}$. These results confirmed that the combination of coriander and $R$. irregularis was not efficient in decreasing ML mobility in our soil conditions. The absence of an inoculum effect could be explained by either an inefficient symbiosis establishment between the root system of coriander and the AMF species or because the hyphae of the AMF did not interact with the extractable ML fraction by binding or sequestering ML or excreting glomalin that creates ML insoluble complexes (Leung et al. 2013). This result is consistent with another study conducted in controlled conditions where the decrease of extractable ML in an aged contaminated soil by the AMF addition could not be shown due to the interaction between glomalin produced by endogenous AMF and soluble ML fraction (Qiao et al. 2015). Concerning, the first hypothesis, it was shown that 
in Europe, soil moisture was the main factor that influences the successful establishment of R. irregularis, a wet soil presenting a favourable ecological niche for the fungus (Kivlin et al. 2017). Thus, the low amount of precipitation observed during the experiment could have constrained the AMF life cycle and its establishment.

\subsection{2) Sage}

Compared to the IS $\mathrm{Zn}$ value (Fig. 4A), the plants increased the extractable soil $\mathrm{Zn}$ and this increase was offset by mycorrhizal inoculation $(\mathrm{p}<0.05)$. Nevertheless, the reduction caused by mycorrhizal inoculation only occurred during the $1^{\text {st }}$ year. On the NI plot, there was a significant decrease $(\mathrm{p}<0.05)$ between the extractable soil $\mathrm{Zn}$ concentrations measured in the years 1 and 2 indicating a plant effect. This effect was occurred at the inflorescence stage of the sage, which could be related to its biennial status and the fact that $\mathrm{Zn}$ is an essential element for plant growth. Overall, this reduction led to a value similar to the IS, showing a negligible impact of the sage and inoculum combination on the solubility of $\mathrm{Zn}$

The extractable soil Cd during the $1^{\text {st }}$ year did not differ from the IS value (Fig. 4B). No plant and no inoculation effects were found. In contrast, during the $2^{\text {nd }}$ year, inoculation reduced extractable Cd $(p<0.05)$, while there was an increase due to plant growth $(\mathrm{p}<0.05)$. The sage at the inflorescence stage (Year 2 NI) increased the extractable soil Cd. These results are in accordance with the high soil Cd mobility (Supplemental Table 2), which may be explained by the negative correlation between soil $\mathrm{pH}$ and the extractable soil $\mathrm{Cd}(\mathrm{p}<0.001, \mathrm{r}=-$ 0.48) indicating that sage acidifies the soil and consequently increases Cd mobility.

The inoculation increased $(\mathrm{P}<0.05)$ the extractable $\mathrm{Pb}$ during the $2^{\text {nd }}$ year $(\mathrm{Fig} .4 \mathrm{C})$. In contrast to $\mathrm{Cd}$, the $\mathrm{Pb}$ mobility was extremely low (Supplemental Table 2). Sage did not change soil $\mathrm{Pb}$ mobility, in contrast to the inoculum which increased it (Supplemental Table 2). Consequently, the extractable soil Pb on the I plot was higher than the IS value at the end of the second culture.

There was a significant decrease in extractable $\mathrm{Cu}(\mathrm{p}<0.05)$ during the $2^{\text {nd }}$ year, which may be due to the biennial status of the plant and the fact that, as with $\mathrm{Zn}, \mathrm{Cu}$ is an essential element (Fig. 4D). Nevertheless, the extractable soil $\mathrm{Cu}$ remained similar to the IS value for this element. The aided phytostabilisation strategy applied to the site did not change soil $\mathrm{Cu}$ mobility, which is around $1 \%$ of the total $\mathrm{Cu}$ (Supplemental Table 2).

Most of the inoculation treatments did not affect the extractable soil $\mathrm{Zn}, \mathrm{Cd}, \mathrm{Pb}$ and $\mathrm{Cu}$ and when there was an effect, it did either not persist for the whole plant harvest cycle or it was insufficient to cause a decrease in 
ML mobility. Similarly, Phanthavongsa et al. (2017) reported inconsistent inoculation effects on extractable soil ML with either increased extractability due to the exudation of organic acids by the roots or a decrease due to the production of glomalin by the AMF.

With the exception of $\mathrm{Cu}$, the extractable soil fractions of $\mathrm{Zn}, \mathrm{Pb}$ and $\mathrm{Cd}$ remained higher than the indicative values (from 24 to 30 times in the case of Cd) (Fig. 4).

\section{3 ) Metal(loid) concentrations in plant and mycorrhizal inoculation effect}

\subsection{1) Coriander}

The $\mathrm{Zn}, \mathrm{Cd}, \mathrm{Pb}$ and, $\mathrm{Cu}$ concentrations were measured in the shoots and seeds of coriander grown on the contaminated soil to assess the pattern of the plant regarding these ML (Fig. 5). They were all above reported values on uncontaminated soils (Ozkutlu 2008; Singh and Garg 2006; Zheljazkov et al. 2008). In addition, they exceeded those measured in the shoots of coriander collected on the uncontaminated site ( $\mathrm{Zn}: 35 ; \mathrm{Cd}: 0.76 ; \mathrm{Cu}$ : 8.5; $\mathrm{Pb}$ : $0.2 \mu \mathrm{g} \mathrm{g}^{-1} \mathrm{DW}$ ) (Fig. 5). The mean concentrations measured in the shoots were, respectively, 25, 9, 2.5 and 1.4 times above the $\mathrm{Pb}, \mathrm{Cd}, \mathrm{Zn}$, and $\mathrm{Cu}$ concentrations measured in uncontaminated conditions.

In agreement with Zheljazkov et al. (2008), the $\mathrm{BCF}_{\text {tot }}$ calculated with the mean shoot Cd concentrations $\left(\mathrm{BCF}_{\text {tot }}>1\right.$; Table 3), indicated an accumulator response for this element. The results of the $\mathrm{BCF}$ tot demonstrated an excluder response for the other ML ( $\mathrm{Zn}, \mathrm{Pb}, \mathrm{Cu}, \mathrm{As}, \mathrm{Cr}, \mathrm{Ni}$ and $\mathrm{Sb}$ ) (Table 3). The Cd accumulator pattern for coriander shoots is in accordance with the fact that the mean $\mathrm{Cd}$ shoot concentration measured on uncontaminated soil was already two times above the ordinary Cd foliar lettuce concentration (Kabata-Pendias, 2011).

The mean concentrations of $\mathrm{Cd}$ and $\mathrm{Pb}$ in the seeds of coriander were higher than those in the shoots of the plant (Fig. 5B, C and D). These results are consistent with previous reports (Smolders 2001; Walker and Waters 2011) which stated that these ML are not translocated into the seeds.

Unlike our study, Redon et al. (2008) reported consistent decreases in the shoot Cd concentrations of Medicago truncatula Gaertn. inoculated with Rhizophagus (formerly Glomus) irregularis . One explanation could be that the mycorrhizal inoculum used in this study was not isolated from a metal-contaminated site, which implies that it was less tolerant to the soil contamination than the indigenous mycorrhizal fungi (Malcova et al. 2003, Orlowska et al. 2005; Hildebrandt et al. 2007). Similarly, excessive ML concentrations may have impeded AMF germination and growth leading to a weak root colonisation by the fungi (Nowak 2007; Sanchez-Castro et al. 2017). 


\subsection{2) Sage}

At the inflorescence stage (Year 2), the relevance of using sage in the production of EO without washing the inflorescences was evaluated. In agreement with the literature (Hibben et al. 1984), the results indicated that there was no washing effect ( $p>0.05$, not shown) on the ML concentrations in the inflorescences of sage, indicating that no additional washing step in the whole distillation process was necessary for this plant. In addition, this result indicated that the dense sage cover observed on the site could reduce the dispersion of ML-contaminated dust, reducing contamination of the aerial portions of the plants. Consequently, the ML concentrations measured for both washed and unwashed inflorescences were pooled and presented all together in the further figures and tables (Fig. 6; Table 4).

In contrast to $\mathrm{Cu}$, the mean $\mathrm{Zn}, \mathrm{Cd}$ and $\mathrm{Pb}$ concentrations measured in the leaves (Year 1) of sage collected on the contaminated site were all above those measured in the leaves of sage from the uncontaminated site ( $\mathrm{Zn}$ : 31; Cd: 0.075; Pb: $0.6 \mu \mathrm{g} \mathrm{g}^{-1} \mathrm{DW}$ ) (Fig. 6). An excluder response of the sage for all the ML studied in this work was indicated by the values of the $\mathrm{BCF}_{\text {tot }}(\mathrm{BCF}<1$, Table 4). The $\mathrm{BCF}$ tot for $\mathrm{Cu}$ ranged between 0.4 and 0.5 (Table 4). For $\mathrm{Zn}$, there was a positive correlation between the extractable $\mathrm{Zn}$ concentration and the $\mathrm{Zn}$ concentrations in leaves and inflorescences of sage $(\mathrm{p}<0.001, \mathrm{r}=0.59)($ Fig. 4$)$, suggesting that the sage has taken up the soluble Zn. On the contrary, the $\mathrm{BCF}$ tot for $\mathrm{Pb}$ was $<<<1$ (Table 4), suggesting a low uptake of the soluble $\mathrm{Pb}$. This assumption was supported by the moderate negative correlation $(\mathrm{p}<0.01, \mathrm{r}=-0.29)$ between the $\mathrm{Pb}$ concentrations in the leaves and inflorescences of sage and $\mathrm{Pb}$ extractable concentration. Irrespective of the inoculation, the inflorescences (Year 2) of the sage concentrated significantly less $\mathrm{Zn}$ and $\mathrm{Pb}$ than its leaves (Year 1) $(\mathrm{p}<0.05)$.

The inoculation led to a reduction of the mean $\mathrm{Zn}, \mathrm{Pb}$ and $\mathrm{Cd}$ concentrations in the leaves of sage (Year 1) $(\mathrm{p}<0.05)$ (Fig. 6A, B and C). A similar effect on the $\mathrm{Pb}$ concentration in maize shoots was shown in laboratory conditions in presence of a $R$. irregularis inoculum at low $\mathrm{Pb}$ soil concentration (Malcova et al. 2003). For Cd, the inoculation effect persisted into Year 2 leading to a reduction of the mean Cd concentrations in the inflorescences of sage (Fig. 6B, p < 0.05), as has already reported in M. truncatula shoots inoculated with $R$. irregularis (Redon et al. 2008).

Despite the reduction of shoot Cd following inoculation, the mean Cd concentrations in the shoots and in the inflorescences were manifold higher than the Cd concentrations measured in the shoots of the sage collected from the uncontaminated site. Heggo and Angle (1990) showed that the same AMF species could have the opposite effect on ML uptake in soybeans depending on the ML extractable concentration in soil. Given that the AMF 
reduced the ML uptake by the sage root system during the $1^{\text {st }}$ year, it is likely that there was successful root colonisation of sage.

\section{4) Metal(loid) concentrations in the residues of distillation and valorisation options}

\subsection{1) Coriander}

Table 5 presents the ML concentrations measured in the residues of coriander after the distillation process. Except for $\mathrm{Cu}$, seed residues had lower ML concentrations than the other aerial parts of the plant. This is in agreement with the results obtained for shoots and seeds metal-concentrations previously reported (Fig. 5). The ML concentrations in the residues of the shoots were higher than the ML concentrations in non-extracted shoots whereas the ML concentrations in the seed residues were similar to the non-extracted seeds (Fig. 5). This may indicate that there is a distillation process effect related to the distilled organ. All ML concentrations in the residues of the shoots and seeds from the contaminated site were above those from the uncontaminated site (unpublished data) (Fig. 5).

The ML concentrations in the coriander residues were compared with the French ML limit values for use as organic soil conditioners (NF U 44-051:2019). Both types of residues from the uncontaminated site could be used as soil conditioners, whereas the residues from the contaminated site exceeded the limit value for Cd (Table 5). As composting results both in a loss of water and a loss of organic matter of up to 50\% (Oudart, 2013), concentrations in ML are proportionally increased in compost. Therefore, use of both shoots and seeds as inputs for producing compost will not be possible. Another option could be the use of the coriander residues in animal fodder. In contrast to the residues from the uncontaminated site, both types of residues from the contaminated site presented Cd concentrations above the Cd limit value set in the Directive on animal fodder (Directive 2002/32/CE of the 7 May 2002 on animal fodder) (Table 5). Even if the coriander residues would have relevant nutritional parameters, their use in animal fodder would be forbidden due to exceedance of the Cd limit. The concentrations of $\mathrm{Pb}$ indicate that this element could also limit reuse.

Biomethane potentials (BMP) of the shoot residue of coriander from the uncontaminated site was of interest (Table 5) as it was similar to that determined for roadside grass (up to $203 \mathrm{Nl}_{\mathrm{CH} 4} \mathrm{~kg}^{-1} \mathrm{VS}$ in André et al. 2019). BMP obtained from the shoot residue of coriander from the contaminated soil were the lowest $(26 \%$ less than the BMP obtained from the shoot residue of coriander from the uncontaminated soil) and could be due to the 
presence of ML in such plant material which could have decreased the production of biomethane by the methanogen microorganisms. No inoculation effect was observed. No previous studies have been conducted on plant distillation residue with biogas production as endpoint. In contrast, a few studies have discussed the possibility to use ML-enriched plant biomass due to phytotechnologies in anaerobic digestion (Thewys et al. 2010a; b; Witters et al. 2012; Cao et al. 2014). ML may be stimulatory or inhibitory to anaerobic microorganisms according to the concentration and speciation of the ML, as well as process-related factors such as $\mathrm{pH}$ and redox potential (Chen et al. 2008). Some results suggested that ML increased gas yield at low concentrations but inhibited gas yield when they were present at high concentrations (Wong and Cheung, 1995). Verma et al. (2007) conducted an experiment on water hyacinth and water chestnut grown in unpolluted water and water with different doses of brass industry effluents that contained increasing concentrations of $\mathrm{Cu}$ and $\mathrm{Cr}$. Biogas yield and biogas rate were increased in presence of brass industry effluents, compared to control conditions but were similar to control conditions at the highest brass industry effluent dose, suggested a stimulatory effect of metals on anaerobic digestion at low-medium dose and an inhibitory effect of metals at high dose. Witters et al. (2012) reported no difference in biogas production potential between maize grown on contaminated soil versus maize grown on uncontaminated soils. Cao et al. (2015) reported that, compared to normal plants with low $\mathrm{Cu}$ content, the plants used in remediation with increased $\mathrm{Cu}$ levels $\left(100 \mathrm{mg} \mathrm{kg}^{-1}\right)$ promoted anaerobic digestion and increased the methane content in biogas.

Due to the low BMP of the coriander residue from the metal-contaminated soil, its use in anaerobic digestion could only be of interest if the distance to the AD platform is around $30 \mathrm{~km}$ to make this option environmentally and economically viable (Zdanevitch et al. 2018). In addition, these residues could complement the inputs in anaerobic digestion if this practice complies with the local regulation in particular regarding the nondilution principle (e.g. Arrêté du 6 juin 2018 for France). Small scale tests on roadside grass showed that no more than $10-15 \%$ by weight of this plant material should be added to the digestion reactor (Zdanevitch et al. 2020). Depending on the physical state of the coriander residues after the oil extraction, they could be used with no more preparation. Nevertheless, due to the high Cd content, the use of Cd-rich residue might impede the valorisation of the digestate as a soil improver or fertiliser.

\subsection{2) Sage}

Leaves (Year 1) and inflorescences (Year 2) of sage were collected to produce EO, leading to plant residues after distillation. Table 5 shows for the contaminated site that all ML concentrations were lower in the inflorescence residues than in the leaf residues. The distillation process effect suggested for coriander was not visible in the case 
of sage except for $\mathrm{Zn}$ and $\mathrm{Pb}$. Indeed, the $\mathrm{Zn}$ and $\mathrm{Pb}$ concentrations in the leaf residues of sage were higher than in the leaves (Fig. 6A and C). The $\mathrm{Cd}, \mathrm{Pb}$ and $\mathrm{Zn}$ concentrations in residues of the leaves and inflorescences from the contaminated site were higher than those measured in the uncontaminated conditions.

All the ML concentrations in residues from the contaminated site were well below the ML limit values set both in the French standard NF U 44-051 (2019) and in the EU regulation on fertilizing products (Regulation (EU) 2019/1009 on the making available on the market of EU fertilizing products), suggesting that these residues could be used in the production of soil conditioners. In contrast to coriander, the residues of sage inflorescences could be used as supplement in animal fodder because neither $\mathrm{Cd}$ nor $\mathrm{Pb}$ concentrations exceeding the limit values set in the Directive (Directive 2002/32/CE of the 7 May 2002 for fodder).

BMPs were lower for both the contaminated and the uncontaminated samples of sage compared to coriander (Table 5): this may come from a higher content in lignin, which is disadvantageous for anaerobic digestion (Triolo and al. 2011, 2012). The recalcitrance of native lignocellulosic biomass makes it resistant to microbial hydrolysis, which reduces the bioconversion efficiency of organic matter into biogas (Xu et al. 2019). Compared to the BMPs of the roadside grass previously shown, the BMPs of the Year 1 residues of sage from the uncontaminated site appeared relevant to contribute to biomethane production. As with coriander residue, BMPs of the Year 1 residue of sage from the contaminated site were even lower (38\% less than the BMP obtained from the leaf residue of sage from the uncontaminated soil), probably due the presence of ML. No inoculation effect was observed. As there is theoretically no restriction due to ML contents, use of these plants for anaerobic digestion could be relevant, especially in areas where the increasing number of anaerobic digestion plants results in resource competition. Kratky and Jirout (2015) suggested that the methane production of the sage residues could be increased by grinding these materials before introduction in the digester, through size reduction, larger surface area and pore size and lower crystallinity. Overall, as the BMP of the sage residue is low, to make this option environmentally and economically viable, the valorisation should be local (Zdanevitch et al. 2018).

Sage residues could be used for producing compost, where the higher content in lignin is an advantage for both the efficiency of the process (aeration) and the quality of the product (stability, mineralisation of the carbon). Composting is a common practice by producers of EO (personal communication) which makes this valorisation option highly relevant.

3.5) Metal(loid) concentrations in essential oils of coriander and sage and mycorrhizal inoculation effect 
Essential oils (EO) of coriander and sage were produced by the industrial producer by steam distillation of the plants at different growth stages once harvested from both contaminated and uncontaminated sites. Before processing, the plants were not washed to mimic industrial practice. The ML concentrations in EO from the biomass produced on the uncontaminated soil were used as reference values, as well as, those for commercial EO (Table 6).

For both plants, irrespective of the plant stage, the ML concentrations in EO were either close or equal to the quantification limits (QL) (Table 6). There was no difference $(\mathrm{p}<0.05)$ between the ML concentrations in coriander EO from both sites and between shoots and seeds. The same results were obtained for sage except for $\mathrm{As}, \mathrm{Cr}$ and $\mathrm{Cu}$ at the leaves stage (Year 1) of the I uncontaminated soil, where the concentrations were above those of the contaminated soil. The inoculation did not influence the ML concentrations in coriander EO but did it in the case of sage at leaves stage for $\mathrm{Cu}$ (increase on the contaminated site, Table 6) and $\mathrm{Cr}$ (decrease on the contaminated site, Table 6).

For both plant species, the lowest ML concentrations occurred in the plant parts usually used for distillation (seeds for coriander and inflorescences for sage). Compared to commercial EO of the same plant species, coriander and sage EO from both sites showed similar or lower ML concentrations. Overall, the ML transfer from biomass to EO was limited and ML concentrations in EO were not correlated with the ML concentrations in the initial biomass. In our experimental conditions, the distillation process used was suitable to limit the metal transfer in EO of coriander and sage and produced EO with a quality similar to that obtained commercially or from uncontaminated soil (Angelova et al. 2016). As reported by Ait-Elallem et al. (2020), this result is explained by the process itself: EO and not ML being extracted through the distillation method. The washing of plant samples did not significantly decrease the ML concentration in the sage EO indicating that a supplemental washing step of the plants before processing was not necessary in our case. In accordance with our results, Angelova et al. (2016), using steam distillation, showed little ML transfer from the seeds of unwashed clary sage to the EO and low ML concentrations in EO. They reported a positive correlation between the soil contamination level and the ML concentration in EO. The ML in their EO being higher than ours due to higher soil ML concentrations compared to ours.

3.6) Summary of the analysis of the metal(loid) fate in the value chain 
Technical decision trees for phytomanagement of sage and coriander are presented in the figure 7 and the supplemental Figure 1, respectively, based on the results of the analysis of the ML fate in the value chain. We showed that sage could be a suitable candidate for phytostabilisation due to its excluder phenotype (Fig. 7). In addition, the mycorrhizal inoculation reduced the $\mathrm{Cd}$ concentration in inflorescences and soil Cd extractable fraction. Moreover, the residues of distillation could be used as soil conditioners or animal fodder, increasing circularity of the agricultural economy (Fig. 7). In contrast, for coriander, the use of a mycorrhizal inoculum affected neither the ML concentrations nor the ML mobility in the soil. Excessive Cd concentrations occurred in the distillation residues, limiting their reuse (Supplemental Fig. 1). Based on ML transfer, EO production on contaminated site with sage and coriander seemed feasible.

\section{4) Conclusions}

This study demonstrated the feasibility of harvesting sage and coriander on a metal(loid)-contaminated soil. Based on the fate of $\mathrm{Cd}, \mathrm{Cu}, \mathrm{Pb}$, and $\mathrm{Zn}$ in the whole value chain, only sage fulfilled all phytomanagement objectives. Although our results showed similar metal(loid) concentrations in essential oil as compared to those obtained from plants grown on an uncontaminated soil, the commercial production of essential oil on contaminated soils depends on other crucial factors such as regulation, consumer perception, economic viability, and waste reduction. Future work should test a broader range of soil amendments to decrease the extractable metal(loid) concentrations in soil and in particular reduce plant Cd-uptake. 


\section{References}

Ait Elallem K, Sobeh M, Boularbah A, Yasri A (2020) Chemically degraded soil rehabilitation process using medicinal and aromatic plants: review. Environ Sci Pollut Res 28: 73-93. https://doi.org/10.1007/s11356-020$10742-\mathrm{y}$

Ali H., Khan E., Sajad M.A (2013) Phytoremediation of heavy metals - Concepts and applications (Review). Chemosphere 91: 869-881. https://doi.org/10.1016/j.chemosphere.2013.01.075

André L, Zdanevitch I, Pineau C, Lencauchez J, Damiano A, Pauss A, Ribeiro T (2019) Dry anaerobic co-digestion of roadside grass and cattle manure at a $60 \mathrm{~L}$ batch pilot scale. Bioresour Technol 289, 121737. https://doi.org/10.1016/j.biortech.2019.121737

Angelova VR, Ivanova RV, Todorov GM, Ivanov KI (2016) Potential of Salvia sclarea L. for phytoremediation of soils contaminated with heavy metals. Int $\mathbf{J}$ of Agric and BiosystEng, 10, No 12. https://doi.org/10.5281/zenodo.1127523

Bago B, Vierheilig H, Piché Y, Azcón-Aguilar C (1996) Nitrate depletion and changes induces by the extraradical mycelium of the arbuscular mycorrhizal fungus Glomus intraradices grown in monoxenic culture. New Phytol 133: 273-280. https://doi.org/10.1111/j.1469-8137.1996.tb01894.x

Bago B, Azcón-Aguilar C (1997) Changes in the rhizospheric pH induced by arbuscular mycorrhiza formation in onion (Allium cepa .L). Z. Pflanzenernähr. Bodenk. 160: 333-339. https://doi.org/10.1002/jpln.19971600231

Bai Z, Gapari T, Ruiperez Gonzalez M, Batjes NH, Mäder P, Bünemann EK, De Goede R, Brussaard L, Xu M, Santos Ferreira CS, Reintam E, Fan H, Mihelič R, Glavan M, Tóth Z (2018) Effect of agricultural practices on soil quality: A review of long-term experiments for Europe and China. Agr Ecosyst Environ 265: 1-7. https://doi.org/10.1016/j.agee.2018.05.028

Baize D (2000) Teneurs totales en métaux lourds dans les sols français. Résultats généraux du programme Aspitet. Le Courrier de l'Environnement de l'INRA 39: 39-54.

Barbieri C, Borsoto P (2018) Chapter 6 Essential Oils: Market and Legislation. In: Hany El-Shemy Potential of Essential Oils, 1st edn. Intechopen, London United Kingdom, pp 107-127.

Bert V, Allemon J, Sajet P, Dieu S, Papin A, Collet S, Gaucher R, Chalot M, Michiels B, Raventos C (2017) Torrefaction and pyrolysis of metal-enriched poplars from phytotechnologies : Effect of temperature and biomass chlorine content on metal distribution in end-products and valorization options. Biomass and Bioenerg 96: 1-11. https://doi.org/10.1016/j.biombioe.2016.11.003 
Burges A, Alkorta I, Epelde L, Garbisu C (2018) From phytoremediation of soil contaminants to phytomanagement of ecosystem services in metal contaminated sites. Int J of Phytoremediat20 (4): $384-397$. https://doi.org/10.1080/15226514.2017.1365340

Cao Z, Wang S, Wang T, Chang Z, Shen Z, Chen Y (2015) Using contaminated plants involved in phytoremediation for anaerobic digestion. Int $\mathbf{J}$ of Phytoremediat 17 (3): 201-207. https://doi.org/10.1080/15226514.2013.876967

Chalot M, Blaudez D, Rogaumes Y, Provent AS, Pascual C (2012) Fate of trace elements during the combustion of phytoremediation wood. Environ Sci and Technolo 46: 13361-13369. https://doi.org/10.1021/es3017478 Chen Y, Cheng JJ, Creamer KS (2008) Inhibition of anaerobic digestion process: a review. Bioressource Technol 99: 4044-64. https://doi.org/10.1016/j.biortech.2007.01.057

Cui H, Zhang X, Zhou H, Zhao C, Lin L (2015) Antimicrobial activity and mechanisms of Salvia sclarea essential oil. Botanical Stud 56. https://doi.org/10.1186/s40529-015-0096-4

Cundy AB, Bardos RP, Puschenreiter M, Mench M, Bert V, Friesl-Hanl W, Müller I, Li XN, Weyens N, Witters N, Vangronsveld J (2016) Brownfields to green fields : Realizing wider benefits from practical contaminant phytomanagement strategies. J of Environ Manag 184: 67-77. https://doi.org/10.1016/j.jenvman.2016.03.028

Dias PP, Waldmann D (2020) Optimisation of the mechanical properties of Miscanthus lightweight concrete. Constand Build Mater 258. https://doi.org/10.1016/j.conbuildmat.2020.119643.

Delplanque M, Collet S, Del Gratta F, Schnuriger B, Gaucher R, Robinson B, Bert V (2013) Combustion of Salix used for phytoextraction: The fate of metals and viability of the process. Biomass and Bioenergy 49: 160-170. https://doi.org/10.1016/j.biombioe.2012.12.026

Denaix L, Semlali RM, Douay F (2001) Dissolved and colloidal transport of Cd, Pb, and Zn in a silt loam soil affected by atmospheric industrial deposition. Environ Pollut 114 (1): 29-38. https://doi.org/10.1016/S02697491(00)00204-9.

Deyris PA, Bert V, Diliberto S, Boulanger C, Petit E, Legrand YM, Grison C (2018) Biosourced polymetallic catalysis : a surprising and efficient means to promote the knoevenagel condensation. Front in Chem 6. https://doi.org/10.3389/fchem.2018.00048

Eikani MH, Golmohammad F, Rowshanzamir S (2007) Subcritical water extraction of essential oils from coriander

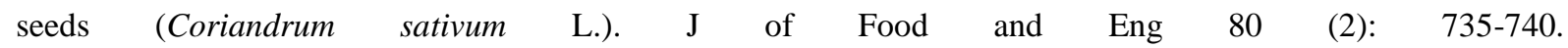
https://doi.org/10.1016/j.jfoodeng.2006.05.015 
El-Alam I, Raveau R, Fontaine J, Verdin A, Laruelle F, Fourmentin S, Chahine R, Makhlouf H and Lounès-Hadj Sahraoui A (2020). Antifungal and Phytotoxic Activities of Essential Oils: In Vitro Assays and Their Potential Use in Crop Protection. Agronomy 10 (6), 825. https://doi.org/10.3390/agronomy10060825

Evangelou MWH , Deram A (2014) Phytomanagement : A Realistic Approach to Soil remediating Phytotechnologies with New Challenges for Plant Science. Intern J of Plant Biol \& Res 2(4) : 1023.

Fatemi H, Esmaielpour B, Sefidkon F, Soltani AA, Nematollahzadeh A (2020) How mycorrhiza symbiosis help coriander (Coriandrum sativum L.) plants growth better under contaminated soil ?. Journal of Plant Nutrition 43 (13):2040-2053. https://doi.org/10.1080/01904167.2020.1766069

Fourrier H., Douay F., Detriche S. (2011) Référentiel Régional Pédologique de Nord-Pas-de-Calais (Etude n³2153). https://www.geoportail.gouv.fr/depot/fiches/INRA/QOljXSgoQGi2wr0NJOqV.pdf ; http://gissol.fr/gissol/fiches_geoportail/brunisols.pdf.

Gartler J, Robinson B, Burton K, Clucas L (2013) Carbonaceous soil amendments to biofortify crop plants with zinc. Sci of the Total Environ 465: 308-313. https://doi.org/10.1016/j.scitotenv.2012.10.027

Heggo A, Angle JS (1990) Effects of vesicular-arbuscular mycorrhizal fungi on heavy metal uptake by soybeans. Soil Biol. Biochem. 22 ( 6) : 865-869. https://doi.org/10.1016/0038-0717(90)90169-Z

Hibben CR, Hagar SS, Mazza CP (1984) Comparison of cadmium and lead content of vegetable crops grown in urban and suburban gardens. Environ Pollut 7: 71-80. https://doi.org/10.1016/0143-148X(84)90038-7

Hildebrand U, Regvar M, Bothe H (2007) Arbuscular mycorrhiza and heavy metal tolerance. Phytochemistry, 68 : 139-146. https://doi.org/10.1016/j.phytochem.2006.09.023

Hinsinger P, Plassard C, Tang C, Jaillard B (2003) Origins of root-mediated pH change in the rhizosphere and their responses to environmental constraints: A review. Plant and Soil 248:43-59. https://doi.org/10.1023/A:1022371130939

Hooper MJ, Glomb SJ, Harper DD, Hoelzle TB, McIntosh LM, Mulligan DR (2015) Integrated risk and recovery monitoring of ecosystem restorations on contaminated sites. Integr Environ Assess and Manag 12 (2): $284-295$. https://doi.org/10.1002/ieam.1731

Jeannin T, Yung L, Evon P, Labonne L, Ouagne P, Lecourt M, Cazaux D, Chalot M, Placet V (2020) Native stinging nettle (Urtica dioica L.) growing spontaneously under short rotation coppice for phytomanagement of trace element contaminated soils: Fibre yield, processability and quality. Ind Crops and Products 145. https://doi.org/10.1016/j.indcrop.2019.111997. 
Jisha CK, Bauddh K, Shukla SK (2017) Phytoremediation and bioenergy production efficiency of medicinal and aromatic plants. In : K. Bauddh et al(eds). Phytoremediation potential of bioenergy plants. Springer Singapore, pp 287-304.

Kabata-Pendias A. Trace Elements in Soils and "Plants, $4^{\text {th }}$ ed.; Taylor and Francis Group: 2011.

Kidd P, Mench M, Álvarez-LÓpez V, Bert V, Dimitriou I, Friesl-Hanl W, Herzig R, Janssen JO, Kolbas A, Müller I, Neu S, Renella G, Ruttens A, Vangronsveld J, Puschenreiter M (2015) Agronomic Practices for improving gentle remediation of trace element-contaminated soils. Int $\mathbf{J}$ of Phytoremediat17 : 1005-1037. https://doi.org/10.1080/15226514.2014.1003788

Kivlin SN, Muscarella R, Hawkes CV, Treseder KK (2017) The Predictive Power of Ecological Niche Modeling for Global Arbuscular Mycorrhizal Fungal Biogeography. In: Tedersoo L. (eds) Biogeography of Mycorrhizal Symbiosis. Ecological Studies (Analysis and Synthesis), vol 230. Springer, Cham., pp 143-158 https://doi.org/10.1007/978-3-319-56363-3_7

Kratky L, Jirout T (2015) Biomass size reduction machines for enhancing biogas production. Chem. Eng. Technol. 34 (3): 391-399. https://doi.org/10.1002/ceat.201000357

Leung HM, Wang ZW, Ye ZH, Yung KL, Peng XL, Cheung KC (2013) Interactions between arbuscular mycorrhizae and plants in phytoremediation of metal-contaminated soils: A review. Pedosphere 23(5) : 549-563. https://doi.org/10.1016/S1002-0160(13)60049-1

Li X, Christie P (2001) Changes in soil solution $\mathrm{Zn}$ and $\mathrm{pH}$ and uptake of $\mathrm{Zn}$ by arbuscular mycorrhizal red clover in Zn-contaminated soil. Chemosphere 42 (2): 201-207. https://doi.org/10.1016/S0045-6535(00)00126-0

Liedekerke M van, Prokop G, Rabl-Berger S, Kibblewhite M, Louwagie G (2014) European Commission, Joint Research Centre, and Institute for Environment and Sustainability. Progress in the management of contaminated sites in Europe. (Luxembourg: Publications Office).

Malcová R, Vosátka M, Gryndler M (2003) Effects of inoculation with Glomus intraradices on lead uptake by Zea Mays L. and Agrostis capillaris L.. Appl Soil Ecol 23:55-67. https://doi.org/10.1016/S0929-1393(02)00160$\underline{9}$

Mandal S, Mandal M (2015) Coriander (Coriandrum sativum L.) essential oil : Chemistry and biological activity. Asian Pac J of Trop Biomed 5(6) : 421-428. https://doi.org/10.1016/j.apjtb.2015.04.001 
Matasyoh JC, Maiyo ZC, Ngure RM, Chepkorir- R (2009) Chemical composition and antimicrobial activity of the essential oil of Coriandrum sativum. Food Chem. 113(2): 526-529. https://doi.org/10.1016/j.foodchem.2008.07.097

Meers E, Van Slycken S, Adriaensen K, Ruttens A, Vangronsveld J, Du Laing G, Witters N, Thewys T, Tack FMG (2010) The use of bio-energy crops (Zea mays) for 'phytoattenuation' of heavy metals on moderately $\begin{array}{llllllll}\text { contaminated } & \text { soils } & \text { : } & \text { A } & \text { field } & \text { experiment. } & \text { Chemosphere } & 78-41 .\end{array}$ https://doi.org/10.1016/j.chemosphere.2009.08.015

Meite F, Alvarez-Zaldivar P, Crochet A, Wiegert C, Payraudeau S, Imfeld G (2018) Impact of rainfall patterns and frequency on the export of pesticides and heavy-metals from agricultural soils. Science of the Total Environment 616-617: 500-509. https://doi.org/10.1016/j.scitotenv.2017.10.297

Nowak Joanna (2007) Effects of cadmium and lead concentrations and arbuscular mycorrhiza on growth, flowering and heavy metal accumulation in scarlet sage (Salvia splendens sello torreador). Acta Agrobotanica 60 (1) : 79-83.

Orlowska E, Ryszka P, Jurkiewicz A, Turnau K (2005) Effectiveness of arbuscular mycorrhizal fungal (AMF) strains in colonization of plants involved in phytostabilization of zinc wastes. Geoderma 129 (1-2): 92-98. https://doi.org/10.1016/j.geoderma.2004.12.036

Oudart Didier (2013) Modélisation de la stabilisation de la matière organique et des émissions gazeuses au cours du compostage d'effluents d'élevage. Thèse de doctorat, Université de Toulouse (p 90).

Ozkutlu Faruk (2008) Determination of Cadmium and Trace Elements in some spices Cultivated in Turkey. Asian Jof Chem $20: 1081-1088$.

Phanthavongsa P, Chalot M, Papin A, Lacerdat-Didier L, Roy S, Blaudez D, Bert V (2017) Effect of mycorrhizal inoculation on metal accumulation by poplar leaves at phytomanaged sites. Environ and ExpBot 143 : $72-81$. https://doi.org/10.1016/j.envexpbot.2017.08.012

Qiao Y, Crowley D, Wang K, Zhang H, Li H (2015) Effect of biochar and Arbuscular mycorrhiza on bioavailability of potentially toxic elements in an aged contaminated soil. Environ Pollut 206 : 636-643. https://doi.org/10.1016/j.envpol.2015.08.029

Raveau R. (2020) Contribution au développement d'une filière éco-innovante de phytomanagement de sols pollués par les éléments traces : culture de plantes aromatiques et production d'huiles essentielles. Thèse de l'université du littoral côte d'opale, école doctorale des sciences de la matière, du rayonnement et de l'environnement ingénierie des fonctions biologiques (thesis). 
Raveau R, Fontaine J ,Lounès-Hadj Sahraoui A (2020). Essential Oils as Potential Alternative Biocontrol Products against Plant Pathogens and Weeds: A Review. Foods 9, 365. https://doi.org/10.3390/foods9030365

Redon PO, Béhuiristain T, Leyval C (2008) Influence of Glomus intraradices on Cd partitioning in a pot experiment with Medicago truncatula in four contaminated soils. Soil Biol and Biochem 40 (10) : 2710-2712. https://doi.org/10.1016/j.soilbio.2008.07.018

Robinson BH, Banuelos G, Conesa HM, Evangelou MW, Schulin R (2009) The phytomanagement of Trace Elements in soil. Crit Rev in Plant Sci 28(4) : 140-166. https://doi.org/10.1080/07352680903035424

Robinson BH, Anderson CWN, Dickinson NM (2015) Phytoextraction: where's the action? J of Geochem Explor $151:$ 34-40. https://doi.org/10.1016/j.gexplo.2015.01.001

Sánchez-Castro I, Gianinazzi-Pearson V, Cleyet-Mzarel JC, Baudoin E, Tuinen D van (2017) Glomeromycota communities survive extreme levels of metal toxicity in an orphan mining site. Sci of Total Environ 598 : 121 128. https://doi.org/10.1016/j.scitotenv.2017.04.084

Seyedalikhani S, Esperschuetz J, Dickinson NM, Hofmann R, Breitmeyer J, Horswell J, Robinson BH (2019) Biowastes to augment the essential oil production of Leptospermum scoparium and Kunzea robusta in lowfertility soil. Plant Physioland Biochem 137 : 213-221. https://doi.org/10.1016/j.plaphy.2019.02.008 Seyedalikhani S, Esperschuetz K, Dickinson NM, Hofmann R, Breitmeyer J, Horswell J, Paramashivam D, Robinson BH (2020) Biowastes promote essential oil production on degraded soils. Ind Crops and Products 145 : 112108. https://doi.org/10.1016/j.indcrop.2020.112108

Smolders Erik (2001) Cadmium uptake by plants. International Journal of Occupational Medicine and Environmental Health 14(2) : 177-183.

Sterckeman T, Douay F, Proix N, Fourrier H, Perdrix E (2002) Water, Air, and Soil Pollution 135 : $173-194$.

Triolo JM, Pedersen L, Qu H, Sommer SG (2012) Biochemical methane potential and anaerobic biodegradability of non-herbaceous and herbaceous phytomass in biogas production. Bioresour Technol 125: 226-232. https://doi.org/10.1016/j.biortech.2012.08.079

Triolo JM, Sommer SG, Møller HB, Weisbjerg MR, Jiang XY (2011) A new algorithm to characterize biodegradability of biomass during anaerobic digestion: Influence of lignin concentration on methane production potential. Bioresour Technol 102(20): 9395-9402. https://doi.org/10.1016/j.biortech.2011.07.026 
Thewys T, Witters N, Van Slycken SV, Ruttens A, Meers E, Tack FMG, Vangronsveld J (2010) Economic viability of phytoremediation of a cadmium contaminated agricultural area using energy maize. Part I: effect on the farmer's income. Int J of Phytoremediat 12 (7): 650-62. https://doi.org/10.1080/15226514.2010.493187 Thewys T, Witters N, Meers E, Vangronsveld J (2010) Economic viability of phytoremediation of a cadmium contaminated agricultural area using energy maize. Part II: economics of anaerobic digestion of metal contaminated maize in Belgium. Int $\mathrm{J}$ of Phytoremediatn $12 \quad$ (7) $\quad$ : 663-79. https://doi.org/10.1080/15226514.2010.493188

Verma VK, Singh YP, Rai JPN (2007) Biogas production from plant biomass used for phytoremediation of industrial wastes. Bioressour Biotechnol 98 (8): 1664-1669. https://doi.org/10.1016/j.biortech.2006.05.038

Vivek Singh, A.N. Garg, (2006) Availability of essential trace elements in Indian cereals, vegetables and spices using INAA and the contribution of spices to daily dietary intake. Food Chemistry 94 (1) : 81-89.

Walker EL, Waters BM (2011) The role of transition metal homeostasis in plant seed development. CurrOpin in Plant Biol 14 (3): 318-324. https://doi.org/10.1016/j.pbi.2011.03.025

Witters NO, Mendelsohn RO, Van Slycken SV, Weyens N, Schreurs E, Meers E., Tack F, Carleer R, Vangronsveld J (2012) Phytoremediation, a sustainable remediation technology? Conclusions from a case study. I: energy production and carbon dioxide abatement. Biomass Bioenerg; $39 \quad$ : 454-69. https://doi.org/10.1016/j.biombioe.2011.08.016

Wong MH, Cheung YH (1995) Gas production and digestion efficiency of sewage sludge containing elevated toxic metals. Bioressour Technol 54: 261-268. https://doi.org/10.1016/0960-8524(95)00139-5

Xu N, Liu S, Xin F, Zhou J, Jia H, Xu J, Jiang M, Dong W (2019) Biomethane Production From Lignocellulose: Biomass Recalcitrance and Its Impacts on Anaerobic Digestion. Front. Bioeng. Biotechnol. 7 : 191. $\underline{\text { https://doi.org/10.3389/fbioe.2019.00191 }}$

Zdanevitch I, Lencauchez J, Duffo L, Pineau C, Andre L, Ribero T (2018) CARMEN - CaRactérisation des HAP et des métaux dans les herbages fauchés en bord de routes pour la MEthanisatioN. 138 pages (French)

Zdanevitch I, Lencauchez J, Damiano A, André L, Ribeiro T, Pineau C (2020) Valorisation d'herbes de bords de routes par méthanisation. Environ Risque Santé 19 (S1) : 71-76.

Zheljazkov VD, Craker LE, Xing B, Nielsen NE, Wilcox A (2008) Aromatic plant production on metal contaminated soils. Sci of the Total Environ 395 (2-3) : 51-62. https://doi.org/10.1016/j.scitotenv.2008.01.041 
Ziegler-Devin I, Menana Z, Chrusciel L, Chalot M, Bert V, Brosse N (2019) Steam explosion pretreatment of willow grown on phytomanaged soils for bioethanol production. Ind Crops \& Products 140. https://doi.org/10.1016/j.indcrop.2019.111722

REGULATION (EU) 2019/1009 OF THE EUROPEAN PARLIAMENT AND OF THE COUNCIL of 5 June 2019 laying down rules on the making available on the market of EU fertilising products and amending Regulations (EC) No 1069/2009 and (EC) No 1107/2009 and repealing Regulation (EC) No 2003/2003. 
Fig. 1. Location, aerial view and experimental design of the field site.

Fig. 2. A and B: Water $\mathrm{pH}$ in soil with inoculated (I) and non-inoculated (NI) coriander (A) and sage (B) before harvest of aerial shoots (orange), the second sowing (BS) (green) and harvest of seeds (BH) (chocolate) or before harvest of leaves (Year 1, orange) and inflorescences (Year 2, green) in the case of coriander and sage, respectively. The dotted line separates the first and second harvest in the case of coriander (A). The red line corresponds to the mean of the water $\mathrm{pH}$ initially measured in soil - see Table 2 . The box plots indicate the median and the 25 and 75 percentiles; mean \pm SD; Significant differences between conditions are indicated by different letters at the level of $\alpha=0.05$.

Fig. 3. $1 \mathrm{M} \mathrm{NH}_{4} \mathrm{NO}_{3}$-extractable concentration of $\mathrm{Zn}(\mathrm{A}), \mathrm{Cd}(\mathrm{B}), \mathrm{Pb}(\mathrm{C})$ and $\mathrm{Cu}(\mathrm{D})$ in soil with inoculated (I) and non-inoculated (NI) coriander before harvest of shoots (orange), before sowing (BS) (green) and before harvest of seeds (BH) (chocolate) (the box plots indicate the median and the 25 and 75 percentiles; mean $\pm \mathrm{SD}$; the red line corresponds to the reference value in the ISO 19730:2008(E), the blue dashed line corresponds to the value measured before the experimental set up (Table 2)). Significant differences between conditions are indicated by different letters at the level of $\alpha=0.05$.

Fig. 4. $1 \mathrm{M} \mathrm{NH}_{4} \mathrm{NO}_{3}$-extractable concentration of $\mathrm{Zn}(\mathrm{A}) . \mathrm{Cd}(\mathrm{B}) . \mathrm{Pb}(\mathrm{C})$ and $\mathrm{Cu}(\mathrm{D})$ in soil with inoculated (I) and non-inoculated (NI) sage before harvest of leaves (Year 1, orange) and before harvest of inflorescences (Year 2, green) (the box plots indicate the median and the 25 and 75 percentiles; mean $\pm \mathrm{SD}$; the red line corresponds to the reference value in the ISO 19730:2008(E), the blue dashed line corresponds to the value measured before the experimental set up (Table 2)). Significant differences between conditions are indicated by different letters at the level of $\alpha=0.05$.

Fig. 5. Concentration of $\mathrm{Zn}(\mathrm{A}), \mathrm{Cd}(\mathrm{B}), \mathrm{Pb}(\mathrm{C})$ and $\mathrm{Cu}(\mathrm{D})$ in shoots (green) and seeds (orange) of coriander inoculated (I) and non-inoculated (NI) (the box plots indicate the median and the 25 and 75 percentiles; mean \pm $\mathrm{SD}$; the red line corresponds to the reference value measured in the uncontaminated site). Significant differences between conditions are indicated by different letters at the level of $\alpha=0.05$.

Fig. 6. Concentration of $\mathrm{Zn}(\mathrm{A}), \mathrm{Cd}(\mathrm{B}), \mathrm{Pb}(\mathrm{C})$ and $\mathrm{Cu}(\mathrm{D})$ in leaves (Year 1, orange) and inflorescences (Year 2, green) of sage inoculated (I) and non-inoculated (NI) (the box plots indicate the median and the 25 and 75 percentiles; mean $\pm \mathrm{SD}$; the red line corresponds to the reference value measured in the uncontaminated site). Significant differences between conditions are indicated by different letters at the level of $\alpha=0.05$

Fig. 7. Technical decision tree for phytomanagement of sage (aided phytostabilization and EO production).

Supplemental Fig. 1. Technical decision tree for phytomanagement of coriander (aided phytostabilization and EO production). 
Table 1. Plant and soil samples according to the species harvest and soil collection. W: washed and NW: Not washed.

\begin{tabular}{|c|c|}
\hline Date of samplings & Samples \\
\hline April 2017 & Soil (composites) \\
\hline July and September 2017 & Soil (all plots) \\
\hline July 2017 & Coriandrum sativum L. $\left(\right.$ shoots $\left.^{\mathrm{W}}\right)$ \\
\hline September 2017 & Salvia sclarea L. (leaves $\left.{ }^{\mathrm{NW}}\right)$ \\
\hline April 2018 & Soil (coriander plots) \\
\hline July 2018 & Soil (sage plots) \\
\hline July 2018 & Salvia sclarea L. (inflorescences ${ }^{\mathrm{W}+\mathrm{NW}}$ ) \\
\hline August 2018 & Soil (coriander plots) \\
\hline August 2018 & Coriandrum sativum L. $\left(\right.$ seeds $\left.^{\mathrm{W}}\right)$ \\
\hline
\end{tabular}


Table 2. Physicochemical properties, total and $1 \mathrm{M} \mathrm{NH}_{4} \mathrm{NO}_{3}$-extractable $\mu \mathrm{g} \mathrm{g}^{-1}$ of DS) concentrations of $\mathrm{Cd}, \mathrm{Zn}$, $\mathrm{Cu}, \mathrm{Pb}, \mathrm{As}, \mathrm{Cr}, \mathrm{Ni}$ and $\mathrm{Sb}$ in the soils of the contaminated and uncontaminated field sites. Values are means \pm SD. 


\begin{tabular}{|c|c|c|c|}
\hline \multicolumn{2}{|c|}{ Parameters } & Contaminated & Uncontaminated \\
\hline \multicolumn{2}{|c|}{$\mathrm{pH}-\mathrm{H}_{2} \mathrm{O}$} & $7.86 \pm 0.13$ & $7.1 \pm 0.52$ \\
\hline \multirow{8}{*}{$\begin{array}{c}\text { Total } \\
\text { (mg kg }{ }^{-1} \text { ) }\end{array}$} & $\mathrm{Cd}$ & $7 \pm 0.4(0.12 \pm 0.04)$ & $0.4 \pm 0.03(0.01 \pm 0.006)$ \\
\hline & $\mathrm{Zn}$ & $443 \pm 12(0.95 \pm 0.33)$ & $48 \pm 2(0.61 \pm 0.35)$ \\
\hline & $\mathrm{Cu}$ & $27 \pm 3(0.29 \pm 0.11)$ & $16 \pm 0.3(0.2 \pm 0.11)$ \\
\hline & $\mathrm{Pb}$ & $394 \pm 16(0.07 \pm 0.03)$ & $22 \pm 2(0.03 \pm 0.03)$ \\
\hline & As & $16 \pm 2(0.01 \pm 0.004)$ & $9 \pm 0.6(0.007 \pm 0.002)$ \\
\hline & $\mathrm{Cr}$ & $59 \pm 3(0.1 \pm 0.1)$ & $50 \pm 3(0.008 \pm 0.003)$ \\
\hline & $\mathrm{Ni}$ & $25 \pm 1.8(0.05 \pm 0.01)$ & $16 \pm 1(0.16 \pm 0.36)$ \\
\hline & $\mathrm{Sb}$ & $5 \pm 0.3(0.05 \pm 0.01$ & $0.7 \pm 0.05(0.006 \pm 0)$ \\
\hline \multicolumn{2}{|c|}{ Clay (\%) } & $26 . \pm 2$ & $14 . \pm 1$ \\
\hline \multicolumn{2}{|c|}{ Silt (\%) } & $53 \pm 10$ & $70 \pm 4$ \\
\hline \multicolumn{2}{|c|}{ Sand (\%) } & $18 \pm 3$ & $17 \pm 3$ \\
\hline \multicolumn{2}{|c|}{ Soil texture (USDA) } & Silty clay loam & Silt loam \\
\hline \multicolumn{2}{|c|}{ Soil type (French classification) ${ }^{*}$} & Fluvisol & Brown soil \\
\hline \multicolumn{2}{|c|}{ Total organic carbon $\left(\mathrm{g} \mathrm{kg}^{-1}\right)$} & $17 \pm 2$ & $10.2 \pm 1.4$ \\
\hline \multicolumn{2}{|c|}{ Organic matter $\left(\mathrm{g} \mathrm{kg}^{-1}\right)$} & $29 \pm 4$ & $18 \pm 2$ \\
\hline \multicolumn{2}{|c|}{$\mathrm{C} / \mathrm{N}$} & $10.5 \pm 0.7$ & $8.6 \pm 0.8$ \\
\hline \multicolumn{2}{|c|}{ CEC Metson $\left(\mathrm{cmol}^{+} \mathrm{kg}^{-1}\right)$} & $183 \pm 50$ & $99 \pm 3$ \\
\hline \multicolumn{2}{|c|}{$\mathrm{CaCO}_{3}(\%)$} & $0.48 \pm 0.13$ & $0.73 \pm 0.34$ \\
\hline \multicolumn{2}{|c|}{$N\left(\mathrm{~g} \mathrm{~kg}^{-1}\right)$} & $1.62 \pm 0.24$ & $1.18 \pm 0.05$ \\
\hline \multicolumn{2}{|c|}{ P available Joret-Hebert $\left(\mathrm{g} \mathrm{kg}^{-1}\right)$} & $0.17 \pm 0.02$ & $0.65 \pm 0.26$ \\
\hline \multicolumn{2}{|c|}{$\mathrm{K}$ available $\left(\mathrm{g} \mathrm{kg}^{-1}\right) \mathrm{K}_{2} \mathrm{O}$} & $0.26 \pm 0$ & $0.21 \pm 0.04$ \\
\hline \multicolumn{2}{|c|}{$\mathrm{Mg}$ available $\left(\mathrm{g} \mathrm{kg}^{-1}\right) \mathrm{MgO}$} & $0.21 \pm 0.02$ & $0.18 \pm 0.07$ \\
\hline \multicolumn{2}{|c|}{$\mathrm{Ca}$ available $\left(\mathrm{g} \mathrm{kg}^{-1}\right) \mathrm{CaO}$} & $6 \pm 0.5$ & $3.5 \pm 1.3$ \\
\hline \multicolumn{2}{|c|}{$\mathrm{Na}$ available $\left(\mathrm{g} \mathrm{kg}^{-1}\right) \mathrm{Na}_{2} \mathrm{O}$} & 0.03 & $0.02 \pm 0$ \\
\hline
\end{tabular}

\footnotetext{
*Fourrier et al. (2011).
} 
Table 3. BCF values for coriander at various stages (shoots, seed) of the plant growth. inoculated (I) and noninoculated $(\mathrm{NI})\left(\mathrm{BCF}\right.$ : calculated as plant part metal concentrations over total $\left(\mathrm{BCF}_{\text {tot }}\right)$ or extractable $\left(\mathrm{BCF}_{\text {extr }}\right)$ metal concentrations in soil). Significant differences between conditions are indicated by the different letters in bold at the level of $\alpha=0.05$ (lower case for $\mathrm{BCF}_{\text {tot }}$; upper case for $\mathrm{BCF}_{\text {extr }}$ ).

\begin{tabular}{|c|c|c|c|c|c|c|c|c|c|}
\hline & & As & Cd & $\mathrm{Cr}$ & $\mathrm{Cu}$ & $\mathbf{N i}$ & $\mathbf{P b}$ & Sb & Zn \\
\hline \multirow{2}{*}{ Shoots I } & $\mathrm{BCF}_{\text {tot }}$ & $\begin{array}{l}0.007 \\
(0.003)\end{array}$ & $\begin{array}{l}0.99 \\
(0.44)^{a}\end{array}$ & $\begin{array}{l}0.022 \\
(0.01)\end{array}$ & $\begin{array}{l}0.46 \\
(0.14)^{\text {a.c }}\end{array}$ & $\begin{array}{l}0.05 \\
(0.015)\end{array}$ & $\begin{array}{l}0.012 \\
(0.004)^{\mathrm{a}}\end{array}$ & $\begin{array}{l}0.006 \\
(0.003)^{\mathrm{a}}\end{array}$ & $\begin{array}{l}0.19 \\
(0.045)\end{array}$ \\
\hline & $\mathrm{BCF}_{\text {extr }}$ & $\begin{array}{l}17 \\
(6)\end{array}$ & $\begin{array}{l}61 \\
(17)^{\mathbf{A}}\end{array}$ & $\begin{array}{l}211 \\
(94)\end{array}$ & $\begin{array}{l}43 \\
(22)\end{array}$ & $\begin{array}{l}28 \\
(11)^{\mathbf{A}}\end{array}$ & $\begin{array}{l}75 \\
(27)^{\mathbf{A}}\end{array}$ & $\begin{array}{l}0.46 \\
(0.21)^{\mathbf{A}}\end{array}$ & $\begin{array}{l}47 \\
(29)^{\mathbf{A}}\end{array}$ \\
\hline \multirow{2}{*}{$\begin{array}{c}\text { Shoots } \\
\text { NI }\end{array}$} & $\mathrm{BCF}_{\text {tot }}$ & $\begin{array}{l}0.009 \\
(0.004)\end{array}$ & $\begin{array}{l}0.94 \\
(0.38)^{\mathrm{a}}\end{array}$ & $\begin{array}{l}0.017 \\
(0.012)\end{array}$ & $\begin{array}{l}0.42 \\
(0.102)^{\mathrm{a}}\end{array}$ & $\begin{array}{l}0.04 \\
(0.014)\end{array}$ & $\begin{array}{l}0.011 \\
(0.004)^{\mathrm{a}}\end{array}$ & $\begin{array}{l}0.005 \\
(0.002)^{\mathrm{a}}\end{array}$ & $\begin{array}{l}0.18 \\
(0.05)\end{array}$ \\
\hline & $\mathrm{BCF}_{\text {extr }}$ & $\begin{array}{l}15 \\
(8)\end{array}$ & $\begin{array}{l}51 \\
(19)\end{array}$ & $\begin{array}{l}169 \\
(104)\end{array}$ & $\begin{array}{l}52 \\
(27)\end{array}$ & $\begin{array}{l}25 \\
(8)^{\mathbf{A}}\end{array}$ & $\begin{array}{l}59 \\
(24)^{\mathbf{A}}\end{array}$ & $\begin{array}{l}0.55 \\
(0.24)\end{array}$ & $\begin{array}{l}34 \\
(21)^{\mathbf{B}}\end{array}$ \\
\hline Seed I & $\mathrm{BCF}_{\text {extr }}$ & $\begin{array}{l}0.007 \\
(0.005) \\
16 \\
(13)\end{array}$ & $\begin{array}{l}0.42 \\
(0.12)^{\mathbf{b}} \\
24 \\
(8)^{\mathbf{B}}\end{array}$ & $\begin{array}{l}0.024 \\
(0.026) \\
214 \\
(232)\end{array}$ & $\begin{array}{l}0.57 \\
(0.12)^{\mathbf{b . c}} \\
50 \\
(12)\end{array}$ & $\begin{array}{l}0.05 \\
(0.023) \\
25 \\
(20)^{\mathbf{B}}\end{array}$ & $\begin{array}{l}0.004 \\
(0.005)^{\mathbf{b}} \\
21 \\
(20)^{\mathbf{B}}\end{array}$ & $\begin{array}{l}0.011 \\
(0.003)^{\mathbf{b}} \\
1.21 \\
(0.51)^{\mathbf{B}}\end{array}$ & $\begin{array}{l}0.2 \\
(0.03) \\
130 \\
(35)^{\mathbf{C}}\end{array}$ \\
\hline \multirow{2}{*}{ Seed NI } & $\mathrm{BCF}_{\text {tot }}$ & $\begin{array}{l}0.008 \pm \\
(0.002)\end{array}$ & $\begin{array}{l}0.45 \\
(0.13)^{\mathbf{b}}\end{array}$ & $\begin{array}{l}0.013 \\
(0.008)\end{array}$ & $\begin{array}{l}0.53 \\
(0.107)^{\mathrm{c}}\end{array}$ & $\begin{array}{l}0.04 \\
(0.013)\end{array}$ & $\begin{array}{l}0.004 \\
(0.002)^{\mathbf{b}}\end{array}$ & $\begin{array}{l}0.010 \\
(0.002)^{\mathbf{b}}\end{array}$ & $\begin{array}{l}0.2 \\
(0.03)\end{array}$ \\
\hline & $\mathrm{BCF}_{\text {extr }}$ & $\begin{array}{l}15 \\
(9)\end{array}$ & $\begin{array}{l}26 \\
(23)^{\mathbf{B}}\end{array}$ & $\begin{array}{l}96 \\
(63)\end{array}$ & $\begin{array}{l}37 \\
(18)\end{array}$ & $\begin{array}{l}15 \\
(5)^{\mathbf{A}}\end{array}$ & $\begin{array}{l}16 \\
(12)^{\mathbf{B}}\end{array}$ & $\begin{array}{l}1.27 \\
(0.73)^{\mathbf{B}}\end{array}$ & $\begin{array}{l}90 \\
(30)^{\mathbf{C}}\end{array}$ \\
\hline
\end{tabular}


Table 4. BCF values for sage at various stages (leaves, Year 1; Inflorescences, Year 2) of the plant growth inoculated (I) and non-inoculated (NI) (BCF: calculated as plant part metal concentrations over pseudo-total $\left(\mathrm{BCF}_{\text {tot }}\right)$ or extractable $\left(\mathrm{BCF}_{\text {extr }}\right)$ metal concentrations in soil). Significant differences between conditions are indicated by the different letters in bold at the level of $\alpha=0.05$ (lower case for $\mathrm{BCF}_{\text {tot }}$; upper case for $\mathrm{BCF}_{\text {extr }}$ ).

\begin{tabular}{|c|c|c|c|c|c|c|c|c|c|}
\hline & & As & Cd & $\mathrm{Cr}$ & $\mathrm{Cu}$ & $\mathbf{N i}$ & $\mathbf{P b}$ & Sb & Zn \\
\hline \multirow{5}{*}{ Leaves I } & \multirow{2}{*}{$\mathrm{BCF}_{\text {tot }}$} & 0.017 & 0.11 & 0.04 & 0.47 & 0.05 & 0.02 & 0.02 & 0.24 \\
\hline & & $(0.004)^{\mathbf{a}}$ & $(0.06)^{\mathbf{a}}$ & $(0.01)^{\mathbf{a}}$ & $(0.05)^{\mathbf{a . b}}$ & $(0.01)^{\mathbf{a}}$ & $(0.008)^{\mathbf{a}}$ & $(0.005)^{\mathbf{a}}$ & $(0.05)^{\mathrm{a}}$ \\
\hline & & & & & & & & & \\
\hline & \multirow[b]{2}{*}{$\mathrm{BCF}_{\text {extr }}$} & 24 & 6 & 351 & 35 & 37 & 149 & 1.4 & 70 \\
\hline & & $(13)^{\mathbf{A}}$ & $(2)^{\mathbf{A}}$ & $(120)^{\mathbf{A}}$ & $(6)^{\mathbf{A}}$ & $(11)^{\mathbf{A}}$ & $(55)^{\mathbf{A}}$ & $(0.2)$ & (36) \\
\hline & \multirow[b]{2}{*}{$\mathrm{BCF}_{\text {tot }}$} & 0.017 & 0.19 & 0.034 & 0.51 & 0.05 & 0.03 & 0.02 & 0.32 \\
\hline Leaves & & $(0.006)^{\mathbf{a}}$ & $(0.06)^{\mathbf{b}}$ & $(0.02)^{\mathbf{a}}$ & $(0.08)^{\mathrm{a}}$ & $(0.02)^{\mathbf{a}}$ & $(0.01)^{\mathbf{b}}$ & $(0.006)^{\mathrm{a}}$ & $(0.07)^{\mathbf{b}}$ \\
\hline \multirow[t]{2}{*}{ NI } & \multirow[b]{2}{*}{$\mathrm{BCF}_{\text {extr }}$} & 37 & 9 & 316 & 33 & 33 & 171 & 2 & 63 \\
\hline & & $(8)^{\mathbf{B}}$ & $(4)^{\mathbf{B}}$ & $(79)^{\mathbf{B}}$ & $(14)^{\mathbf{A}}$ & $(10)^{\mathbf{A}}$ & $(68)^{\mathbf{A}}$ & $(0.6)$ & (42) \\
\hline & \multirow[b]{2}{*}{$\mathrm{BCF}_{\text {tot }}$} & 0.01 & 0.101 & 0.04 & 0.37 & 0.03 & 0.005 & 0.01 & 0.15 \\
\hline Infloresc & & $(0.005)^{\mathbf{b}}$ & $(0.04)^{\mathbf{a}}$ & $(0.02)^{\mathbf{a}}$ & $(0.21)^{\mathbf{b}}$ & $(0.01)^{\mathbf{b}}$ & $(0.002)^{\mathbf{c}}$ & $(0.005)^{\mathbf{b}}$ & $(0.03)^{\mathrm{c}}$ \\
\hline \multirow[t]{2}{*}{ ences I } & \multirow[b]{2}{*}{$\mathrm{BCF}_{\text {extr }}$} & 13 & 5 & 216 & 96 & 12 & 13 & 1.4 & 70 \\
\hline & & $(12)^{\mathrm{C}}$ & $(2)^{\mathbf{A}}$ & $(135)^{\mathbf{A}}$ & $(112)^{\mathbf{B}}$ & $(5)^{\mathbf{B}}$ & $(10)^{\mathbf{B}}$ & $(0.7)$ & (23) \\
\hline \multirow{4}{*}{ ences NI } & \multirow[b]{2}{*}{$\mathrm{BCF}_{\text {tot }}$} & 0.006 & 0.13 & 0.02 & 0.41 & 0.03 & 0.004 & 0.01 & 0.12 \\
\hline & & $(0)^{\mathbf{c}}$ & $(0.05)^{\mathrm{a}}$ & $(0.01)^{\mathbf{b}}$ & $(0.16)^{\mathbf{a}, \mathbf{b}}$ & $(0.01)^{\mathbf{b}}$ & $(0.001)^{\mathbf{c}}$ & $(0.004)^{\mathbf{b}}$ & $(0.03)^{\mathbf{c}}$ \\
\hline & \multirow[b]{2}{*}{$\mathrm{BCF}_{\text {extr }}$} & 16 & 5 & 194 & 223 & 11 & 17 & 1.7 & 56 \\
\hline & & $(5)^{\mathrm{C}}$ & $(3)^{\mathbf{A}}$ & $(114)^{\mathbf{A}}$ & $(219)^{\mathbf{A}}$ & $(5)^{\mathbf{B}}$ & $(9)^{\mathbf{B}}$ & $(0.7)$ & (27) \\
\hline
\end{tabular}


Table 5. Concentrations ( $\mu \mathrm{g} \mathrm{g}^{-1} \mathrm{DM}$ ) of $\mathrm{As}, \mathrm{Cd}, \mathrm{Cr}, \mathrm{Cu}, \mathrm{Hg}, \mathrm{Ni}, \mathrm{Pb}, \mathrm{Sb}$ and $\mathrm{Zn}$ in distillation residues obtained from shoots and seeds of coriander and leaves (Year 1), inflorescences (Year 2) of sage, inoculated (I) and noninoculated (NI), from contaminated and uncontaminated soils. Significant differences between conditions are indicated by the different letters in bold at the level of $\alpha=0.05$. BMP: Bio-Methane Potential $\left(\mathrm{Nl}_{\mathrm{CH} 4} \mathrm{x} \mathrm{kg}^{-1} \mathrm{SV}\right)$.

\begin{tabular}{|c|c|c|c|c|c|c|c|c|}
\hline Coriander & As & Cd & $\mathrm{Cr}$ & $\mathbf{C u}$ & $\mathbf{N i}$ & $\mathbf{P b}$ & $\mathbf{Z n}$ & BMP \\
\hline \multirow{2}{*}{ shoots NI } & 1.16 & 9.1 & 8.9 & 15.4 & 4.7 & 29.8 & 180 & 132.08 \\
\hline & $(0.08)^{\mathbf{a}}$ & $(1.45)^{\mathrm{a}}$ & $(1.36)^{\mathbf{a}}$ & $(1.1)^{\mathrm{a}}$ & $(0.6)^{\mathbf{a}}$ & $(2.3)^{\mathbf{a}}$ & $(12)^{\mathbf{a}}$ & \multirow[b]{3}{*}{145.18} \\
\hline \multirow[b]{2}{*}{ Shoots I } & 1.69 & 8.8 & 10.5 & 19.8 & 5.3 & 43.1 & 209 & \\
\hline & $(0.17)^{\mathbf{b}}$ & $(1.14)^{\mathrm{a}}$ & $(2.8)^{\mathbf{a}}$ & $(1.2)^{\mathbf{b}}$ & $(1)^{\mathbf{a}}$ & $(2.8)^{\mathbf{b}}$ & $(26)^{a}$ & \\
\hline \multirow{2}{*}{ Seed NI } & \multirow{2}{*}{$\mathrm{QL} * \mathbf{c}$} & 3.7 & 1.2 & 18.1 & 1.5 & 0.9 & 112 & \multirow[b]{2}{*}{-} \\
\hline & & $(0.44)^{\mathbf{b}}$ & $(0.11)^{\mathbf{b}}$ & $(2.1)^{\mathbf{a} . \mathbf{b}}$ & $(0.1)^{\mathbf{b}}$ & $(0.07)^{\mathbf{c}}$ & $(11)^{\mathbf{b}}$ & \\
\hline \multirow[b]{2}{*}{ Seed I } & \multirow{2}{*}{$\mathrm{QL} * \mathbf{c}$} & 3.51 & 1.5 & 18.8 & 1.9 & 0.8 & 103 & \multirow[b]{2}{*}{-} \\
\hline & & $(0.37)^{\mathbf{b}}$ & $(0.68)^{\mathbf{b}}$ & $(2.3)^{\mathbf{a . b}}$ & $(0.2)^{\mathbf{b}}$ & $(0.1)^{\mathbf{c}}$ & $(19)^{\mathbf{b}}$ & \\
\hline Shoots (un- & 0.26 & 0.75 & 6.9 & 10.1 & 4 & 0.6 & 49 & \multirow{2}{*}{195.8} \\
\hline soil) & $(0.05)$ & $(0.1)$ & $(2.92)$ & $(1.45)$ & $(1.7)$ & $(0.2)$ & (7) & \\
\hline \multirow{2}{*}{$\begin{array}{l}\text { Seed (un- } \\
\text { contaminated } \\
\text { soil) }\end{array}$} & 0.79 & 0.39 & 21.2 & 17.4 & 10 & 0.6 & 76.45 & \multirow{2}{*}{ - } \\
\hline & $(0.79)$ & $(0.04)$ & (22) & $(4.2)$ & (8.7) & $(0.5)$ & (30) & \\
\hline \multicolumn{9}{|l|}{ Sage } \\
\hline \multirow{2}{*}{ Leaves I } & 0.29 & 1.24 & 2.5 & 11.1 & 1.3 & 13.5 & 164 & \multirow{2}{*}{89.61} \\
\hline & $(0.03)^{\mathrm{a}}$ & $(0.07)^{\mathbf{a}}$ & $(0.5)^{\mathrm{a}}$ & $(0.7)^{\mathrm{a}}$ & $(0.14)^{\mathrm{a}}$ & $(1.1)^{\mathrm{a}}$ & $(10)^{\mathbf{a}}$ & \\
\hline \multirow{2}{*}{ Leaves NI } & 0.34 & 1.67 & 2.9 & 12.6 & 1.7 & 18.3 & 183 & \multirow{2}{*}{72.85} \\
\hline & $(0.09)^{\mathbf{a}}$ & $(0.09)^{\mathbf{b}}$ & $(1)^{\mathbf{a}}$ & $(0.6)^{\mathbf{b}}$ & $(0.55)^{\mathrm{a}}$ & $(2.7)^{\mathbf{b}}$ & $(9)^{\mathbf{b}}$ & \\
\hline Inflorescences & 0.11 & 0.69 & 1.6 & 7.6 & 0.7 & 3.3 & 57 & \multirow[b]{4}{*}{-} \\
\hline NI & $(0.01)^{\mathbf{b . c}}$ & $(0.03)^{\mathbf{c}}$ & $(0.4)^{\mathbf{a}}$ & $(0.6)^{\mathrm{c}}$ & $(0.17)^{\mathbf{b . c}}$ & $(0.7)^{\mathbf{c}}$ & $(3)^{\mathbf{c}}$ & \\
\hline \multirow[b]{2}{*}{ Inflorescences I } & 0.18 & 0.82 & 1.7 & 7.9 & 0.55 & 3.7 & 67 & \\
\hline & $(0.04)^{\mathbf{c}}$ & $(0.18)^{\mathbf{c}}$ & $(0.1)^{\mathrm{a}}$ & $(0.9)^{\mathbf{c}}$ & $(0.03)^{\mathbf{b}}$ & $(0.7)^{\mathbf{c}}$ & $(5)^{c}$ & \\
\hline
\end{tabular}




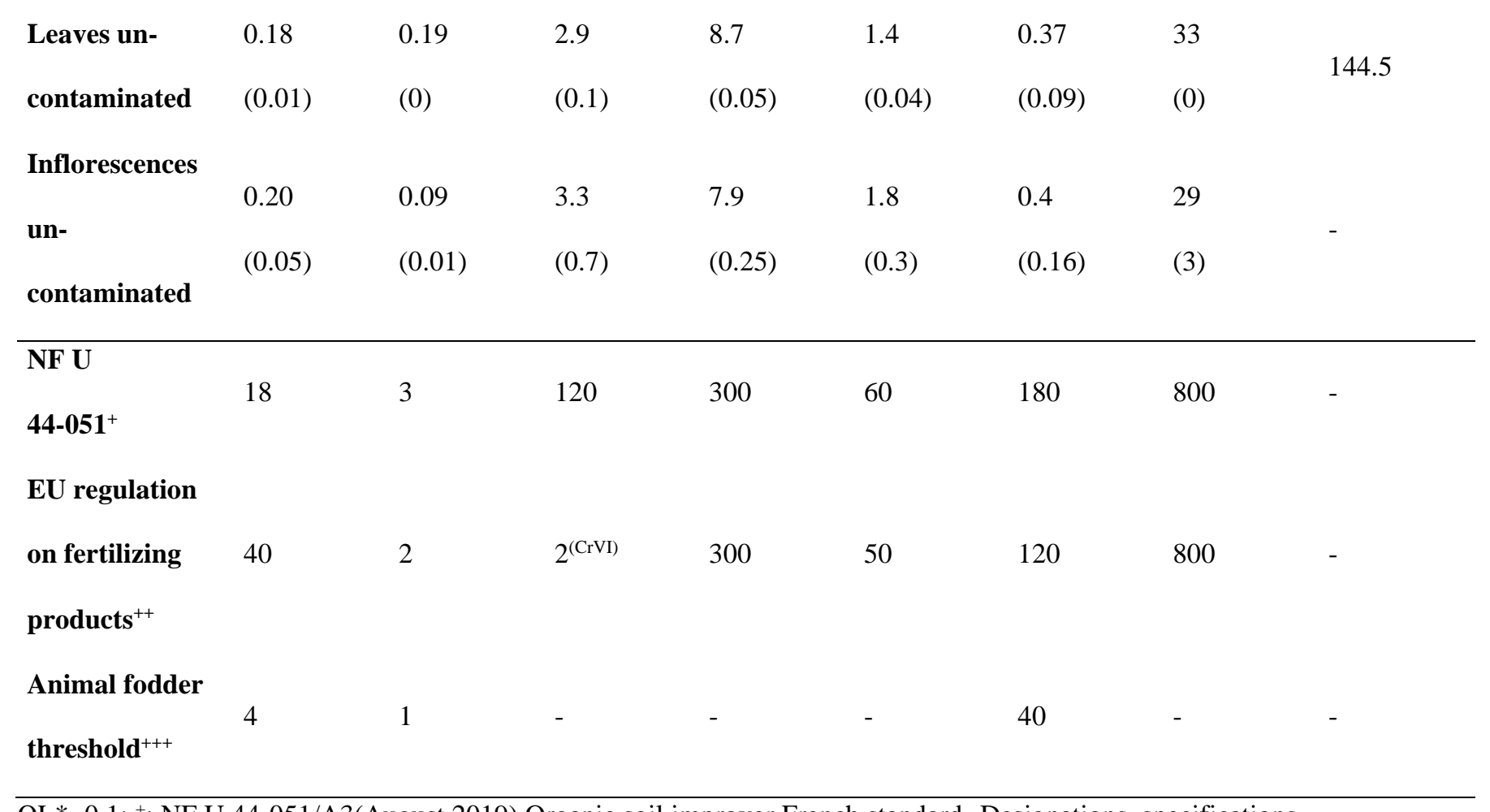

$\mathrm{QL}^{*}=0.1{ }^{+}$: NF U 44-051/A3(August 2019) Organic soil improver French standard- Designations, specifications and marking - Additional elements; ${ }^{++}$: REGULATION (EU) 2019/1009 OF THE EUROPEAN PARLIAMENT AND OF THE COUNCIL of 5 June 2019 laying down rules on the making available on the market of EU fertilizing products; ${ }^{+++}$: Directive 2002/32/CE of the 7 May 2002. 
Table 6. Concentrations of metal(loid)s in essential oils obtained from shoots and seeds of coriander and from leaves (Year 1) and inflorescences (Year 2) of sage, inoculated (I) and non-inoculated (NI) contaminated and uncontaminated soils. Significant differences between conditions are indicated by the different letters in bold at the level of $\alpha=$ 0.05. Commercial refers to commercial oils. QL = Quantification Limit.

\begin{tabular}{|c|c|c|c|c|c|c|c|c|c|c|c|c|c|c|c|c|}
\hline & As & & Cd & & $\mathrm{Cr}$ & & $\mathrm{Cu}$ & & $\mathbf{N i}$ & & $\mathbf{P b}$ & & $\mathbf{S b}$ & & $\mathbf{Z n}$ & \\
\hline Coriander & Shoots & Seed & Shoots & Seed & Shoots & Seed & Shoots & Seed & Shoots & Seed & Shoots & Seed & Shoots & Seed & Shoots & Seed \\
\hline I contaminated & $\begin{array}{l}0.01 \\
(0.00)^{\mathbf{a}}\end{array}$ & QL & QL & QL & $\begin{array}{l}0.036 \\
(0.009)^{\mathbf{a}}\end{array}$ & $\begin{array}{l}0.022 \\
(0.009)\end{array}$ & $\begin{array}{l}0.056 \\
(0.1)^{\mathrm{a}}\end{array}$ & QL & $\begin{array}{l}0.06 \\
(0.03)\end{array}$ & QL & QL & QL & QL & QL & QL & QL \\
\hline NI contaminated & $\begin{array}{l}0.013 \\
(0.004)^{\mathbf{a}} \\
\text { b }\end{array}$ & QL & QL & QL & $\begin{array}{l}0.034 \\
(0.03)^{\mathrm{a}}\end{array}$ & $\begin{array}{l}0.018 \\
(0.003)\end{array}$ & $\mathrm{QL}^{\mathrm{a}}$ & QL & $\begin{array}{l}0.064 \\
(0.04)\end{array}$ & QL & $\begin{array}{l}0.073 \\
(0.109)\end{array}$ & QL & QL & QL & $\begin{array}{l}0.094 \\
(0.145)\end{array}$ & QL \\
\hline$I_{\text {uncontaminated }}$ & $\begin{array}{l}0.014 \\
(0.002)^{\mathbf{a}} \\
\text { b }\end{array}$ & QL & QL & QL & $\mathrm{QL}^{\mathbf{b}}$ & $\begin{array}{l}0.017 \\
(0.002)\end{array}$ & $\mathrm{QL}^{\mathrm{a}}$ & QL & QL 0 & $\begin{array}{l}0.017 \\
(0.007)\end{array}$ & QL & QL & QL & QL & $\begin{array}{l}0.081 \\
(0.122)\end{array}$ & $\begin{array}{l}0.072 \\
(0.038)\end{array}$ \\
\hline $\begin{array}{l}\text { NI } \\
\text { uncontaminated }\end{array}$ & $\begin{array}{l}0.01 \\
(0.002)^{\mathrm{a}}\end{array}$ & QL & QL & QL & $\begin{array}{l}0.021 \\
(0.02)^{\mathrm{a}}\end{array}$ & $\begin{array}{l}0.019 \\
(0.003)\end{array}$ & $\mathrm{QL}^{\mathrm{a}}$ & QL & $\begin{array}{l}0.031 \\
(0.001)\end{array}$ & QL & $\begin{array}{l}0.072 \\
(0.106)\end{array}$ & QL & QL & QL & $\begin{array}{l}0.075 \\
(0.111)\end{array}$ & $\begin{array}{l}0.054 \\
(0.007)\end{array}$ \\
\hline
\end{tabular}




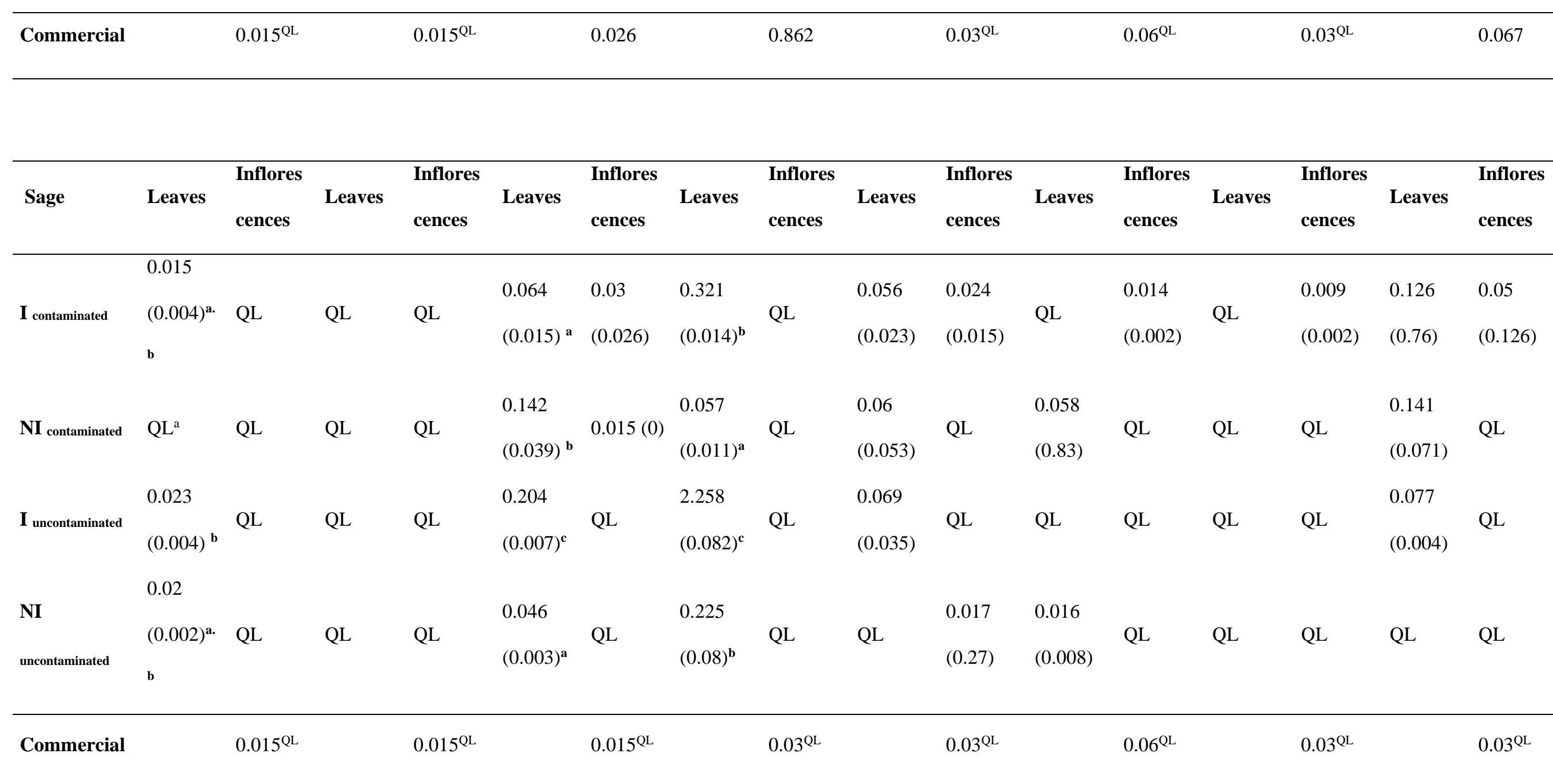


Figure caption

The R 3.5.2 software was used to create the boxplot figure (Fig. 2,3,4,5,6). The microsoft powerpoint software was used to create the fig. 1. The Fig. 7 and Supplemental Fig. 1 were created with the microsoft publisher software.

\section{Fig. 1}

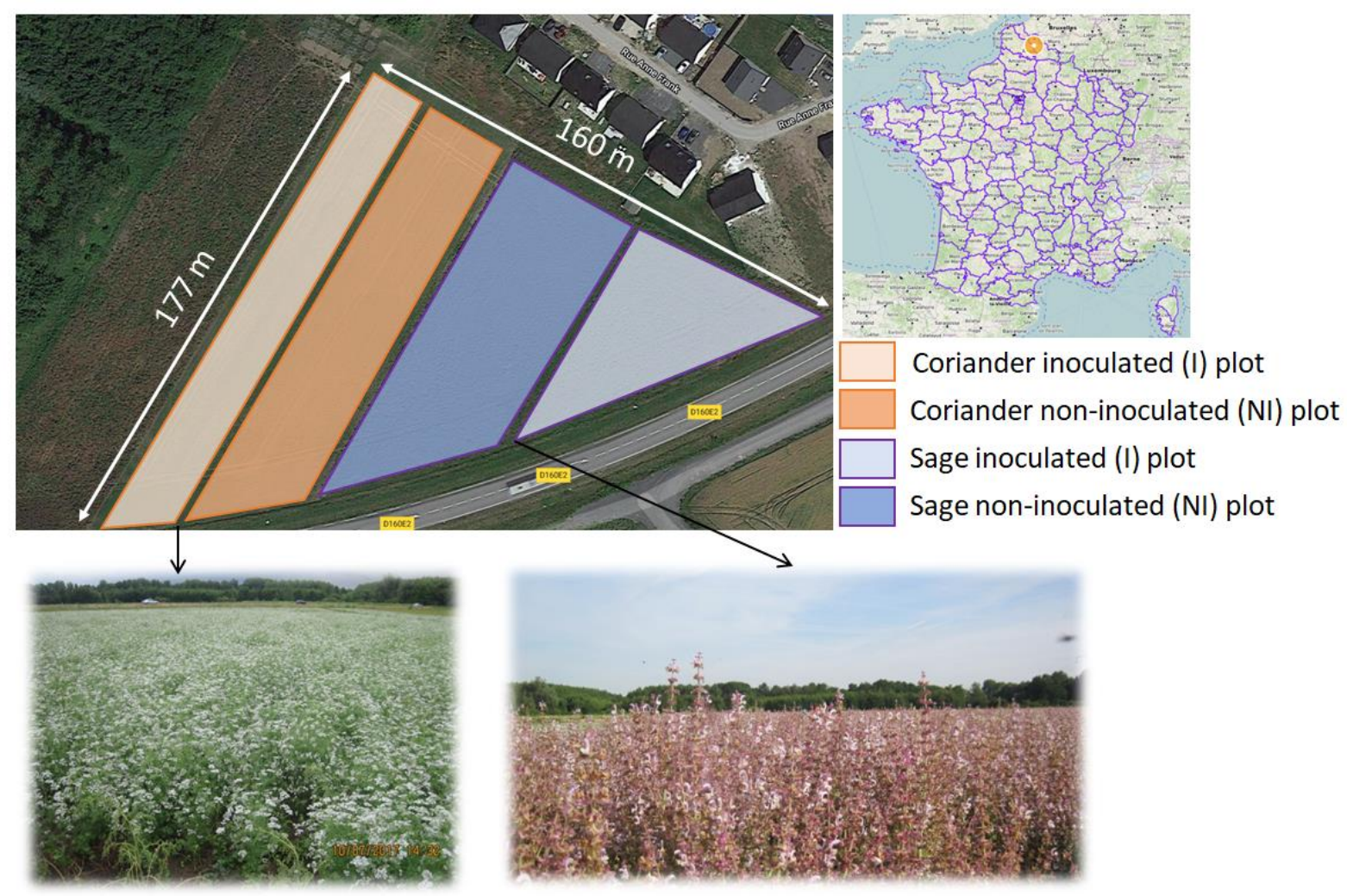


Fig. 2

pH

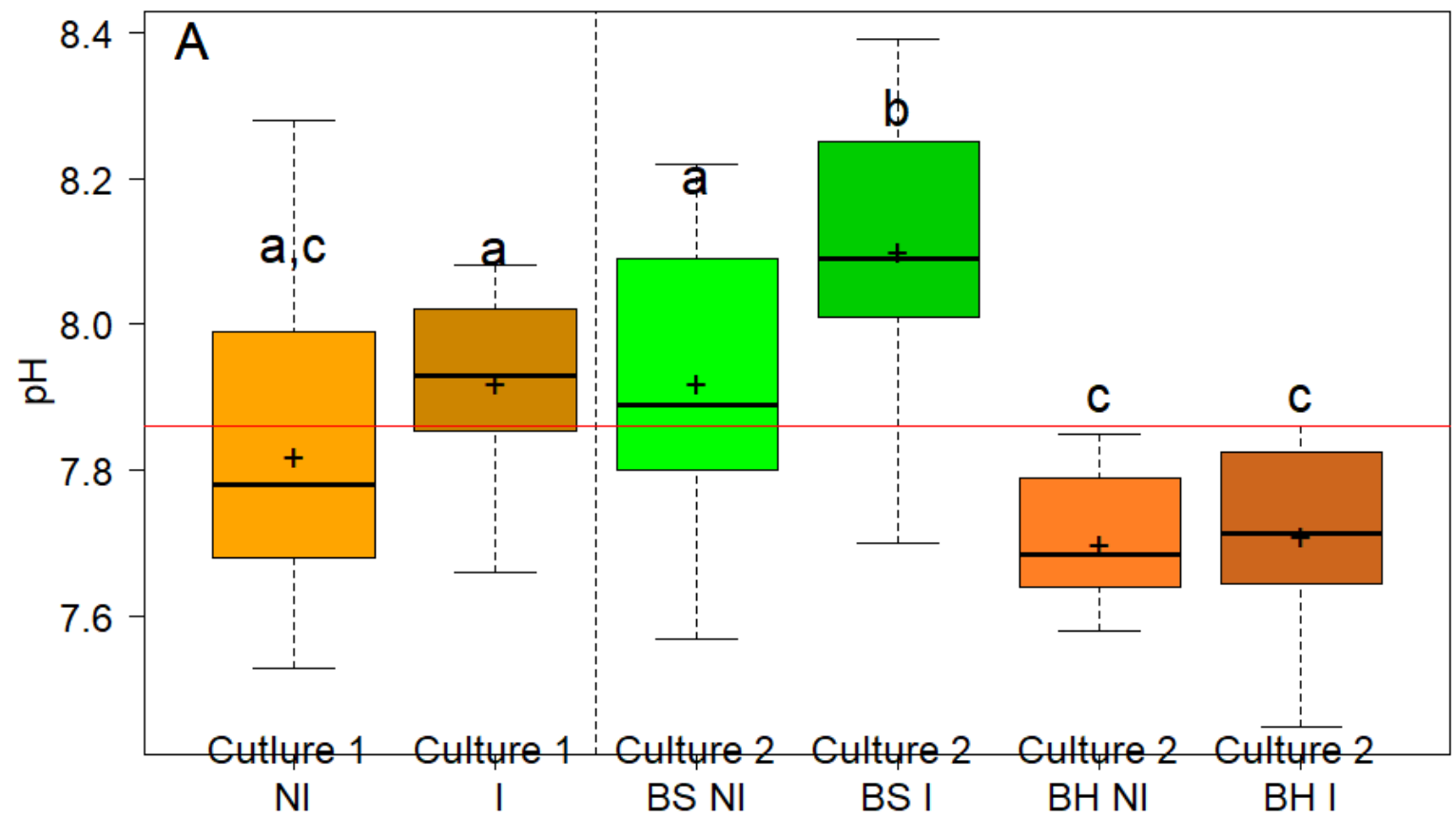

pH

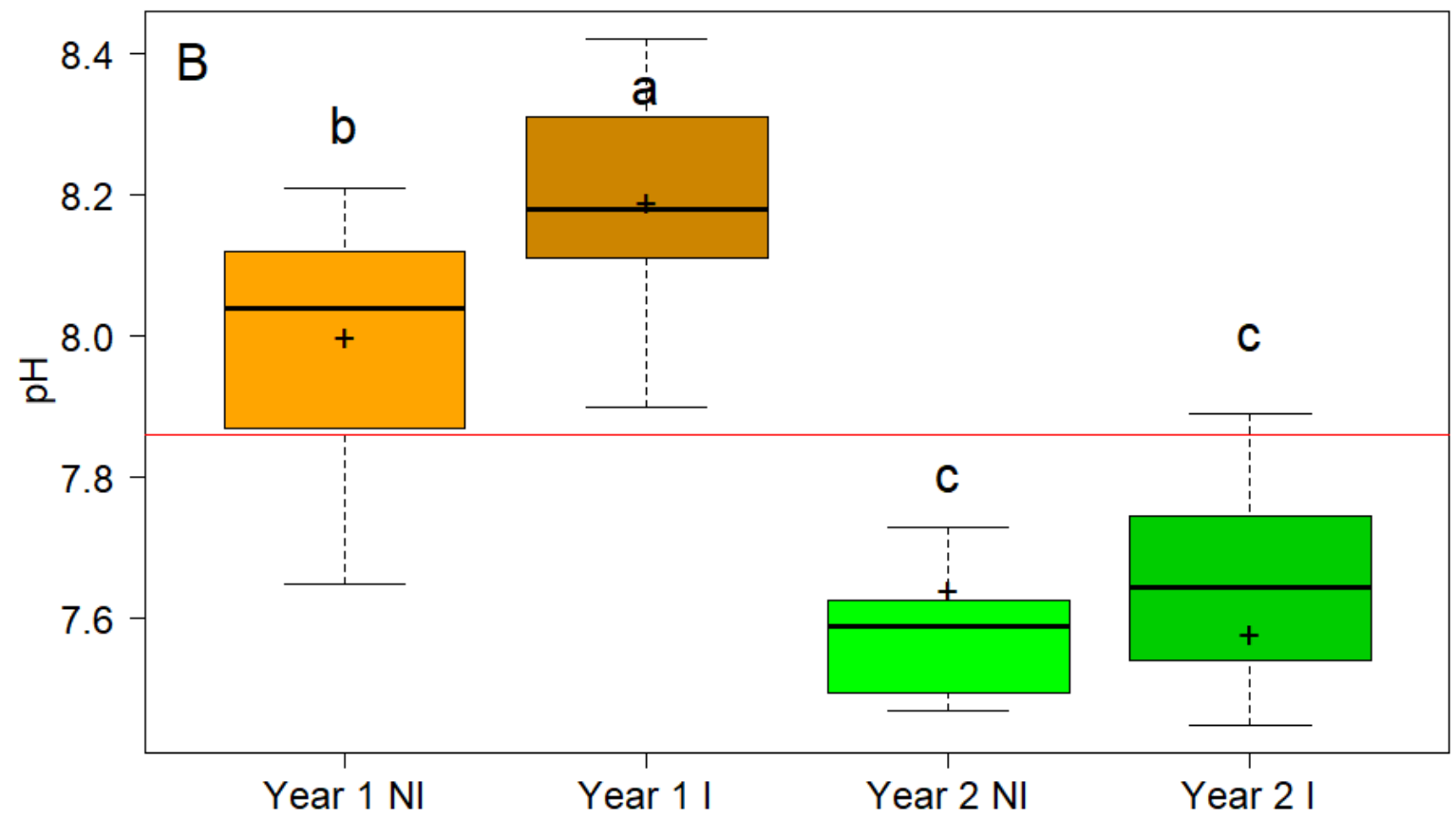


Zn

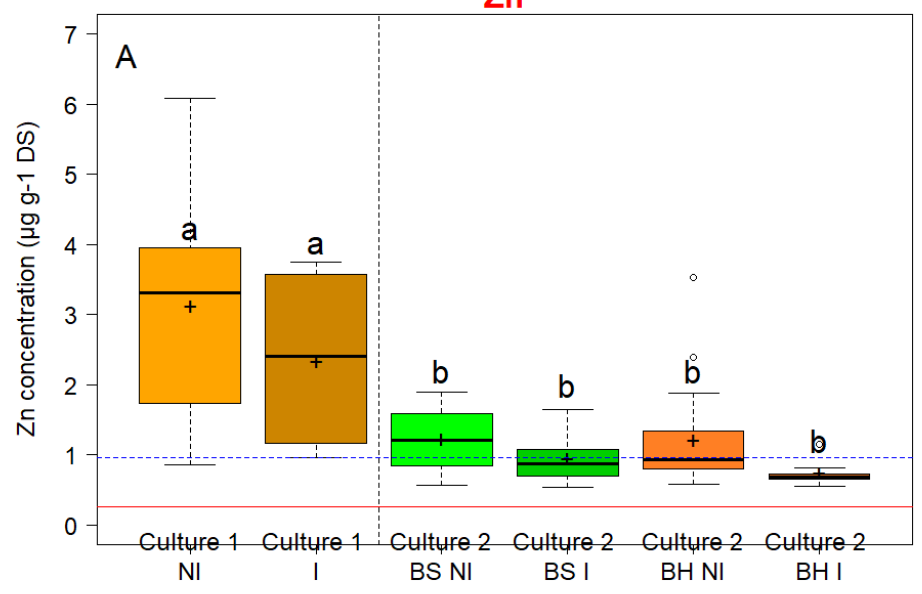

$\mathrm{Pb}$

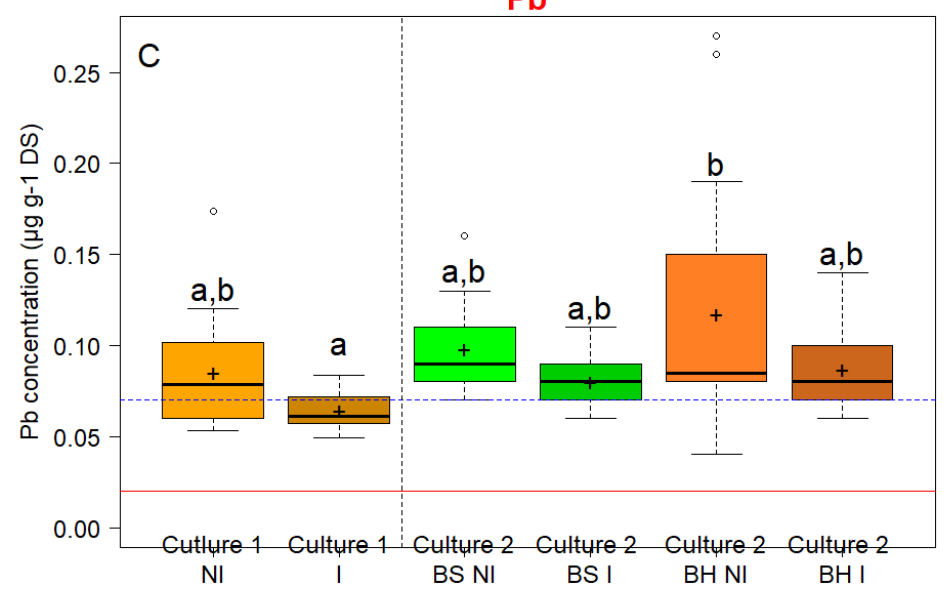

Cd

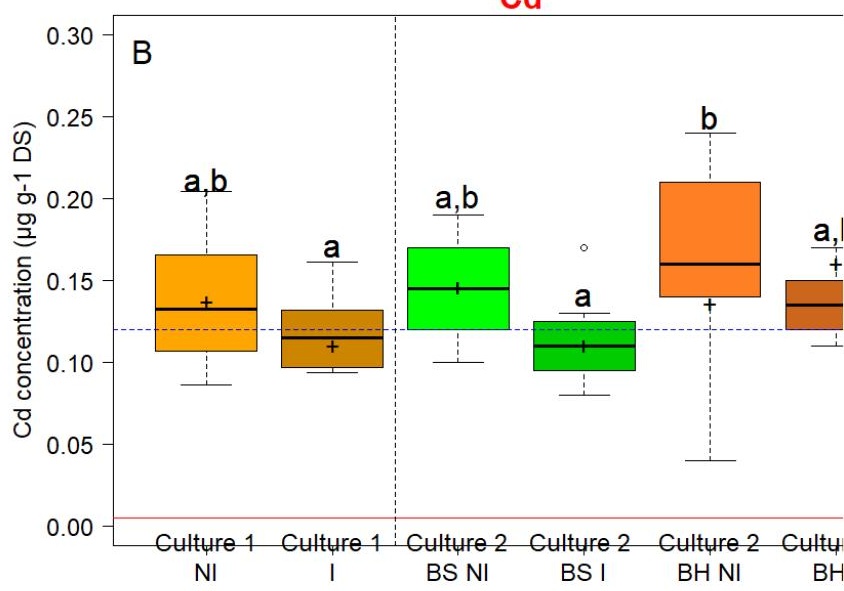

$\mathrm{Cu}$

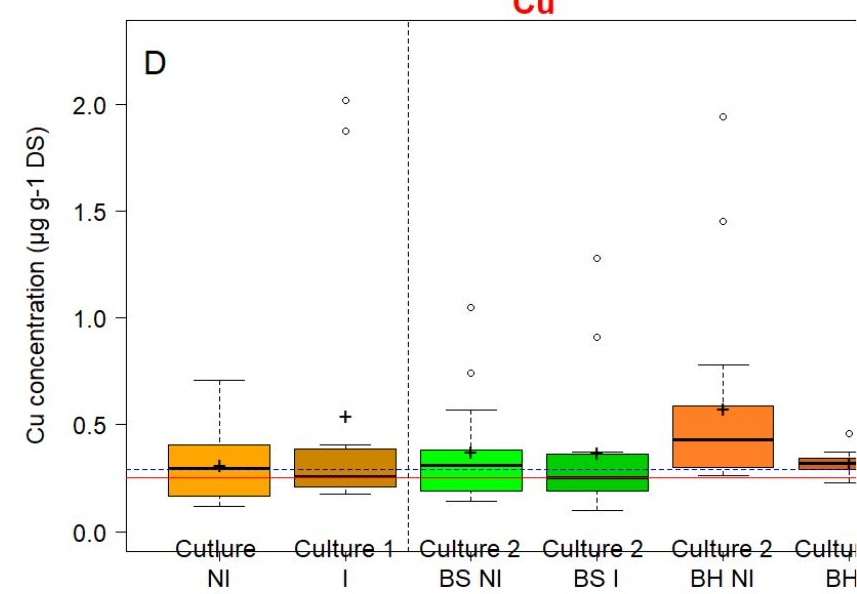


Fig. 4

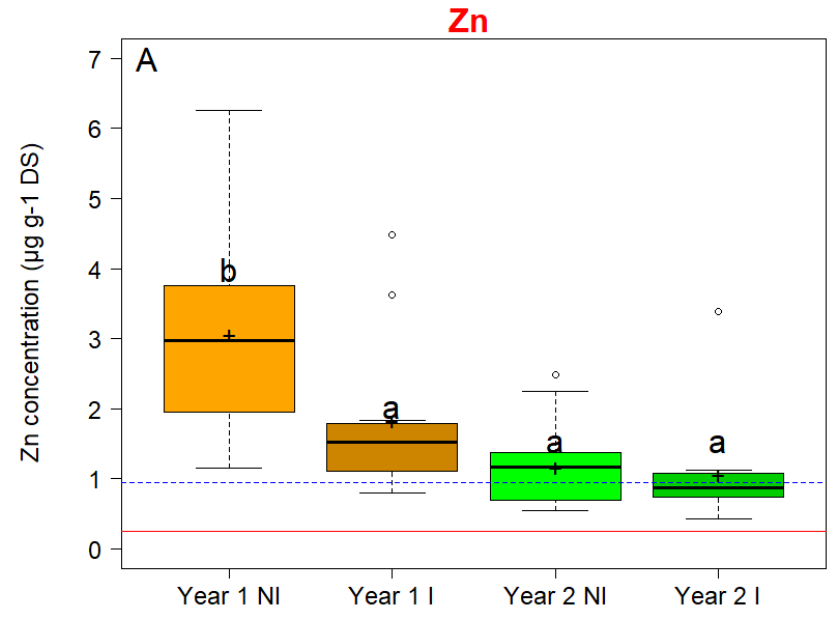

$\mathrm{Pb}$

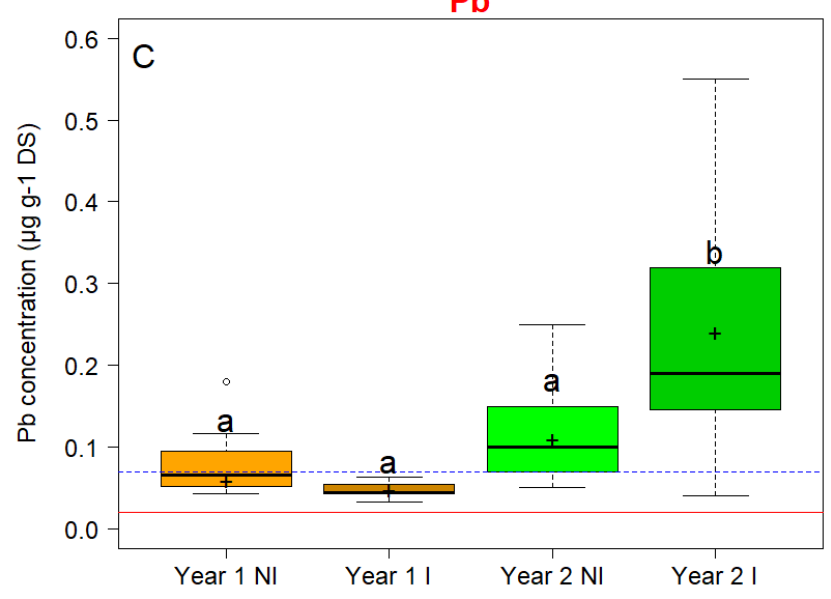

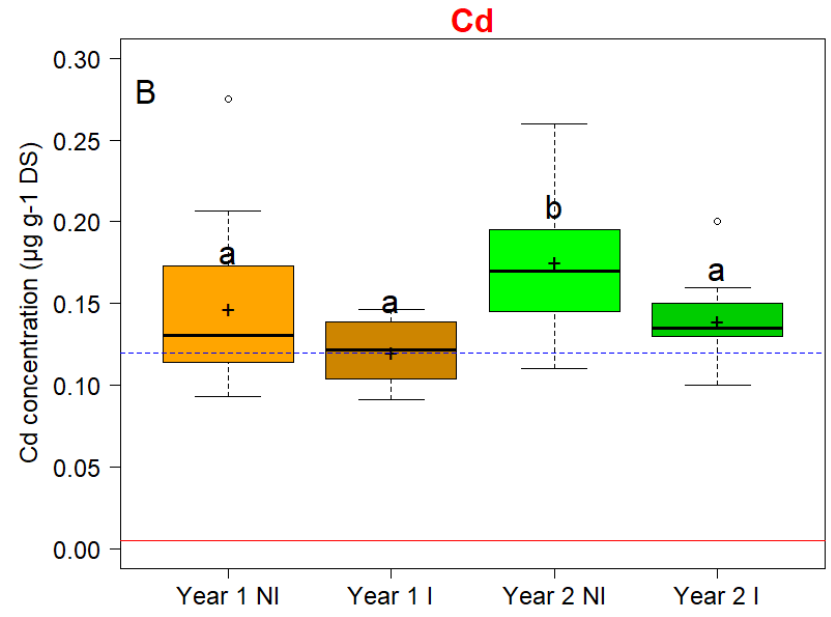

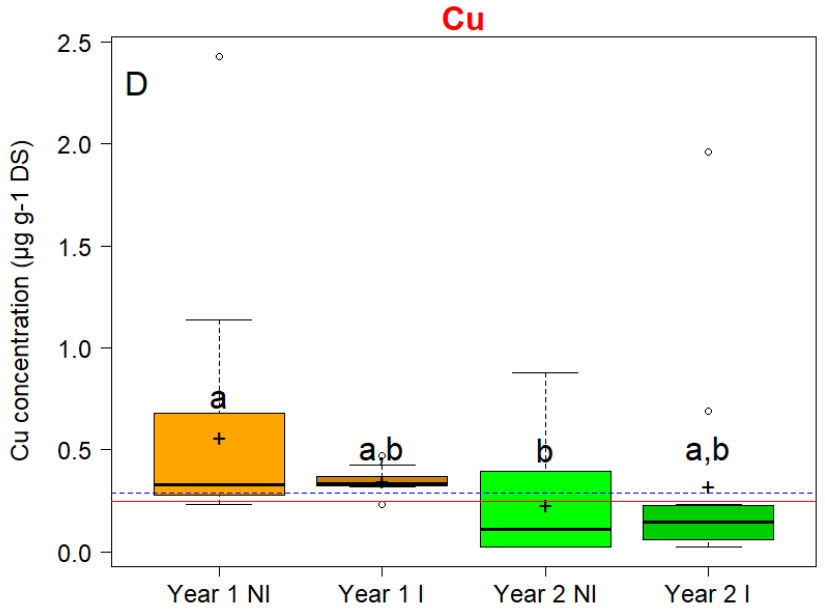


Zn

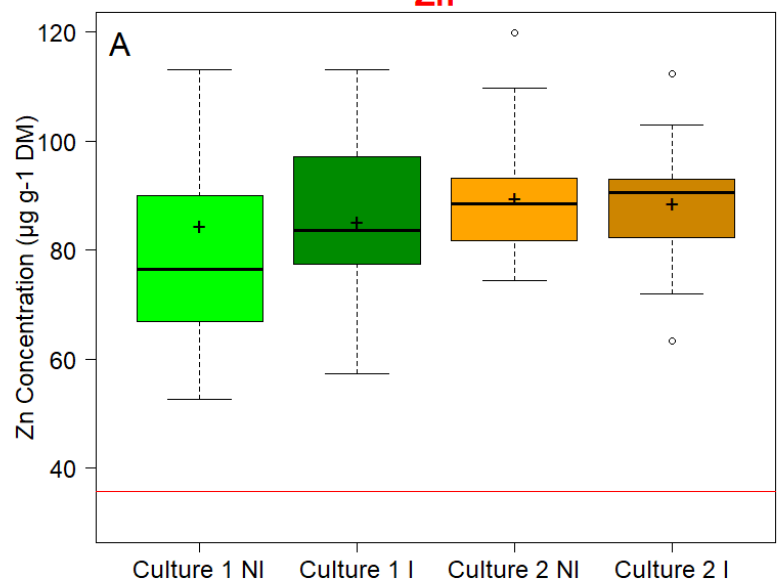

$\mathrm{Pb}$

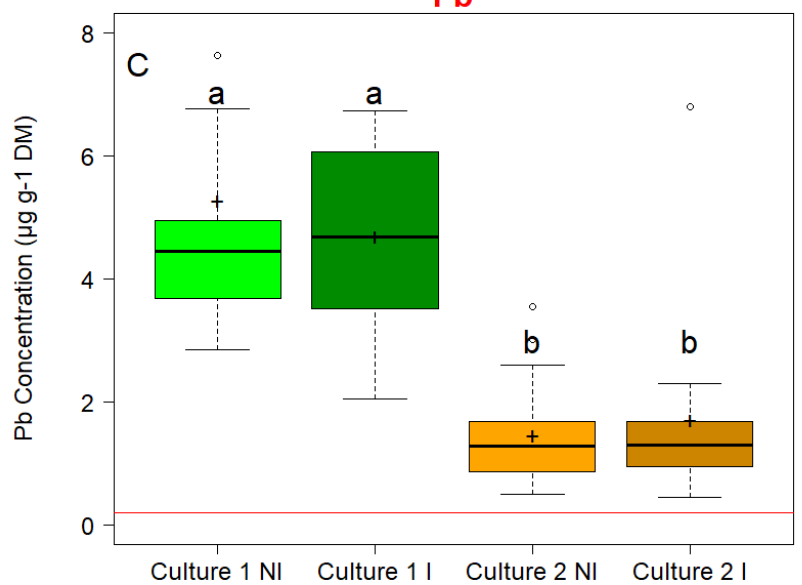

Cd

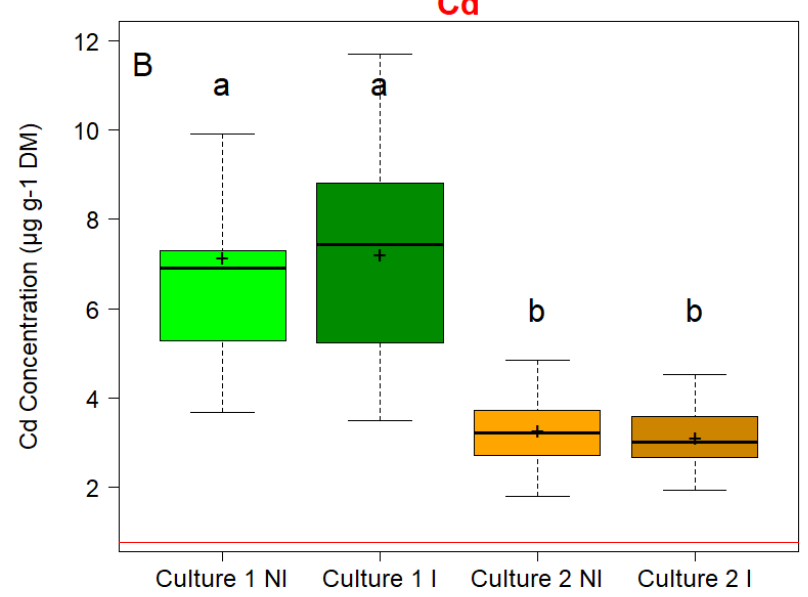

$\mathrm{Cu}$

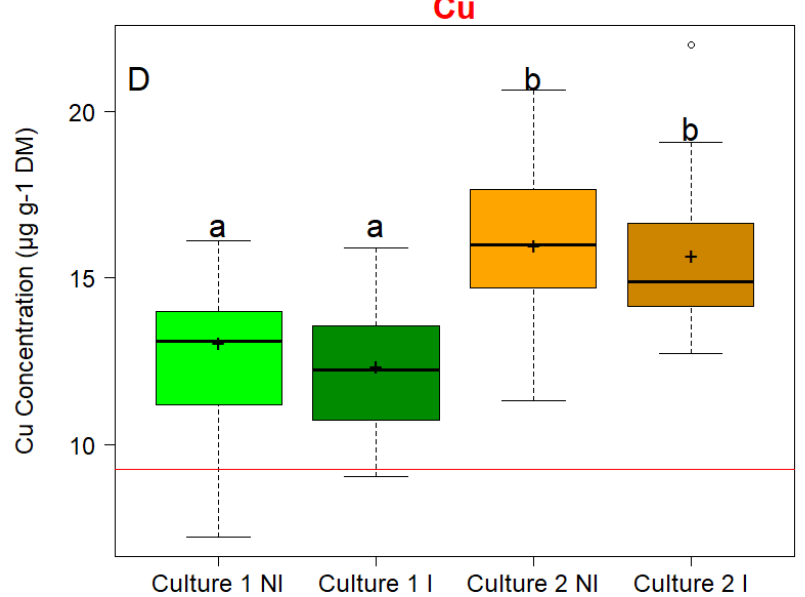


Fig. 6
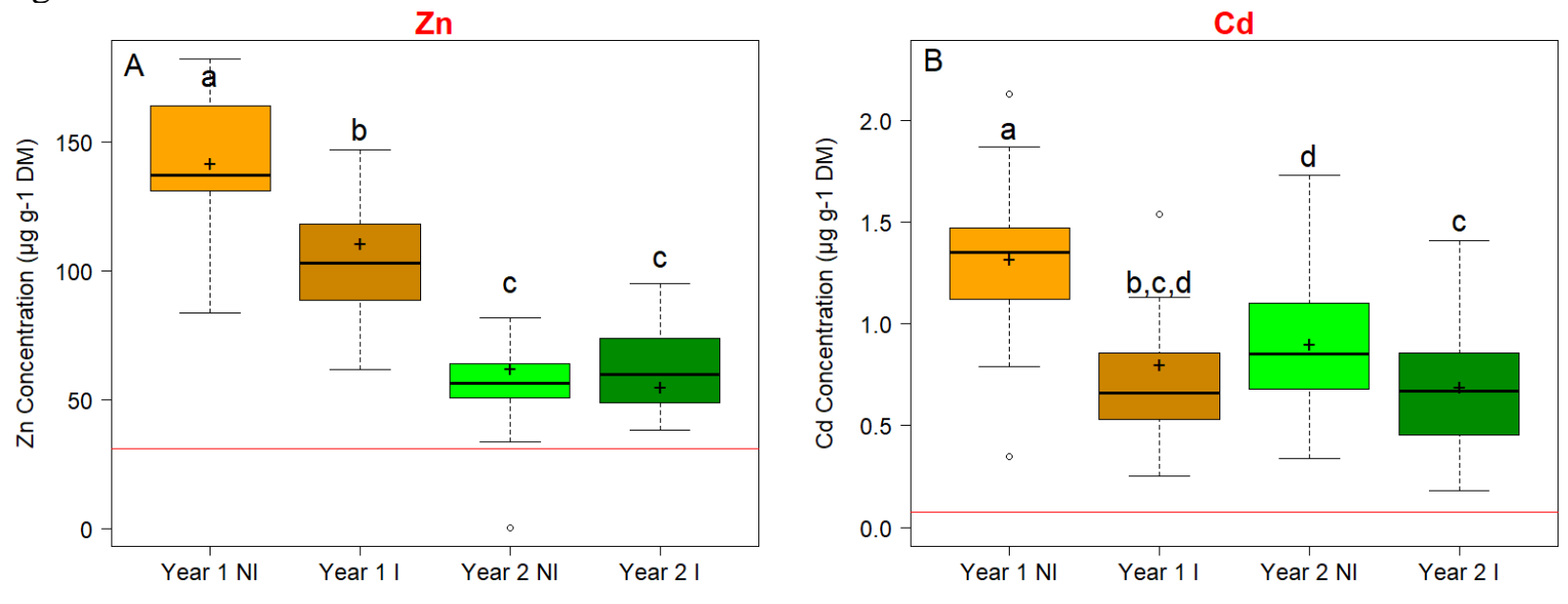

$\mathrm{Pb}$
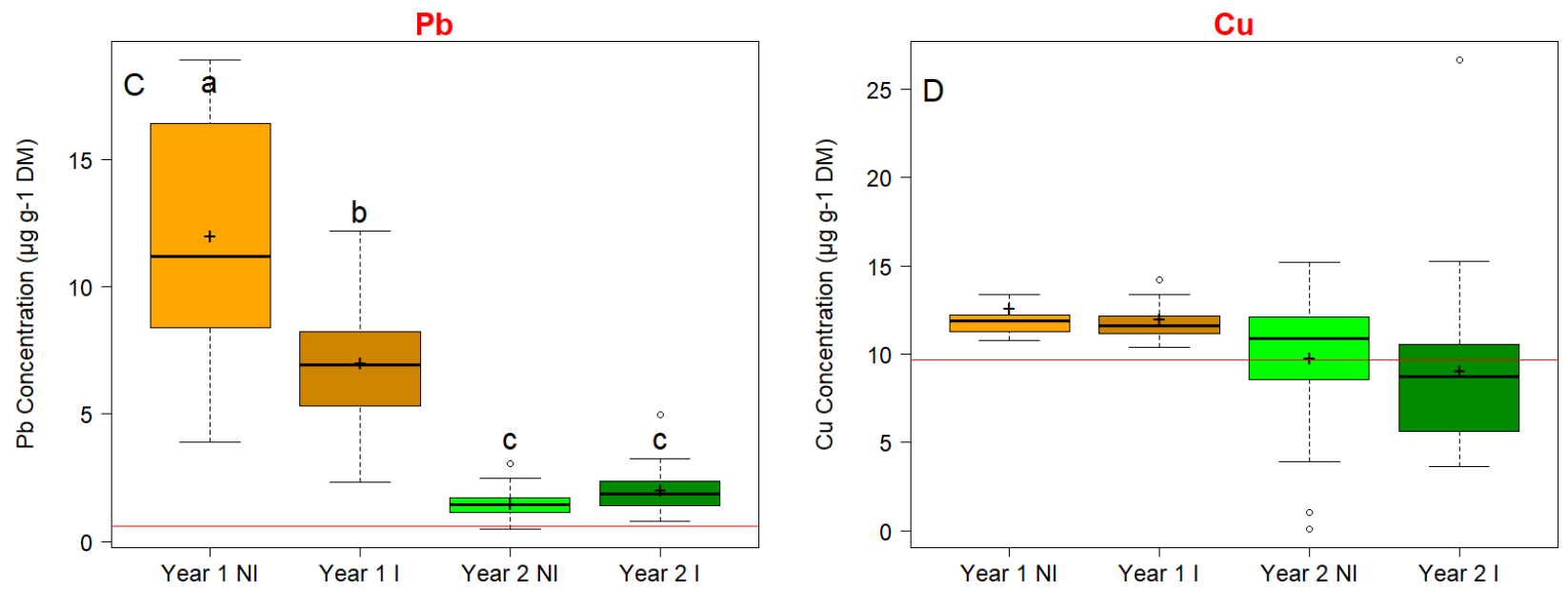
Fig. 7

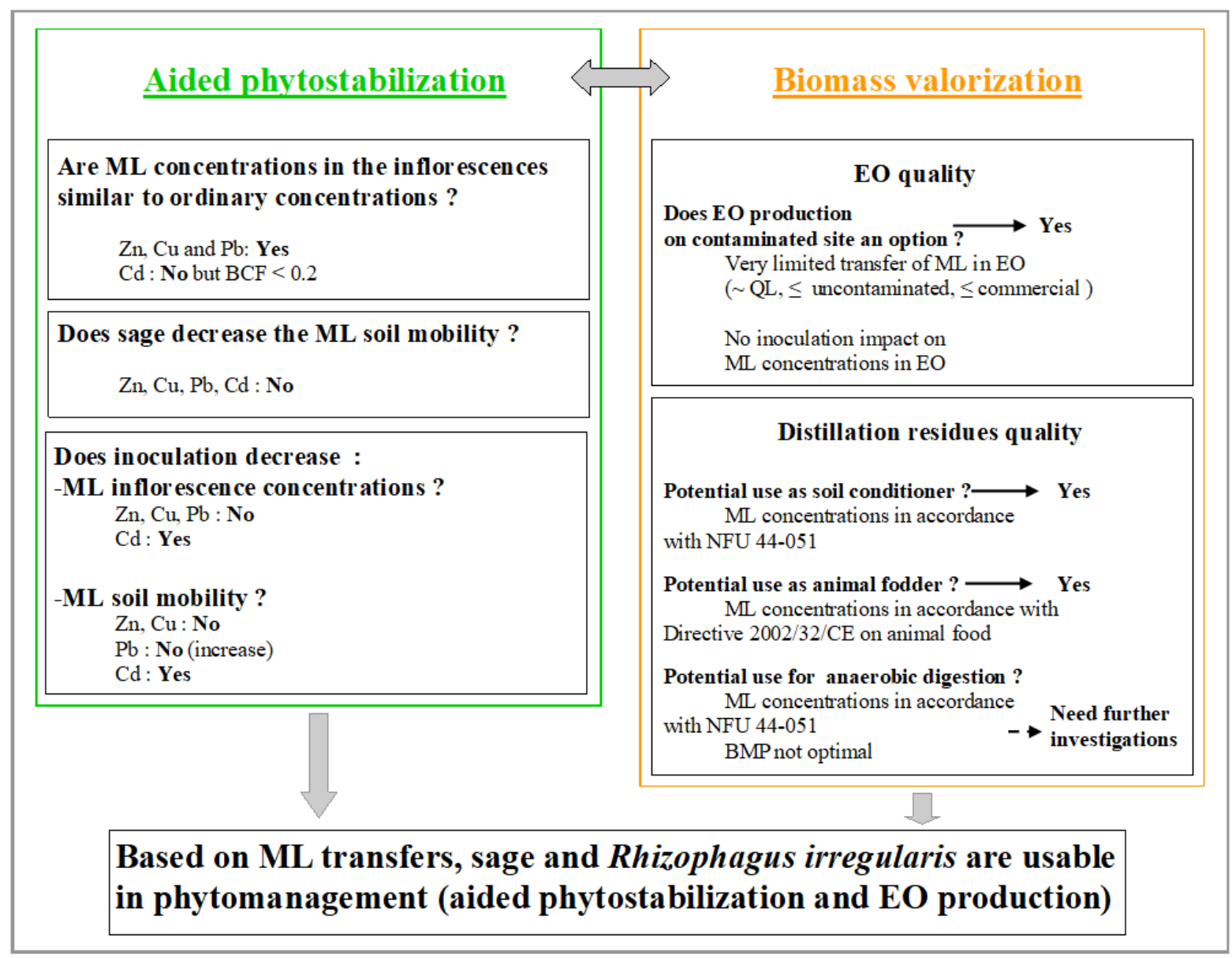


Supplemental Fig. 1

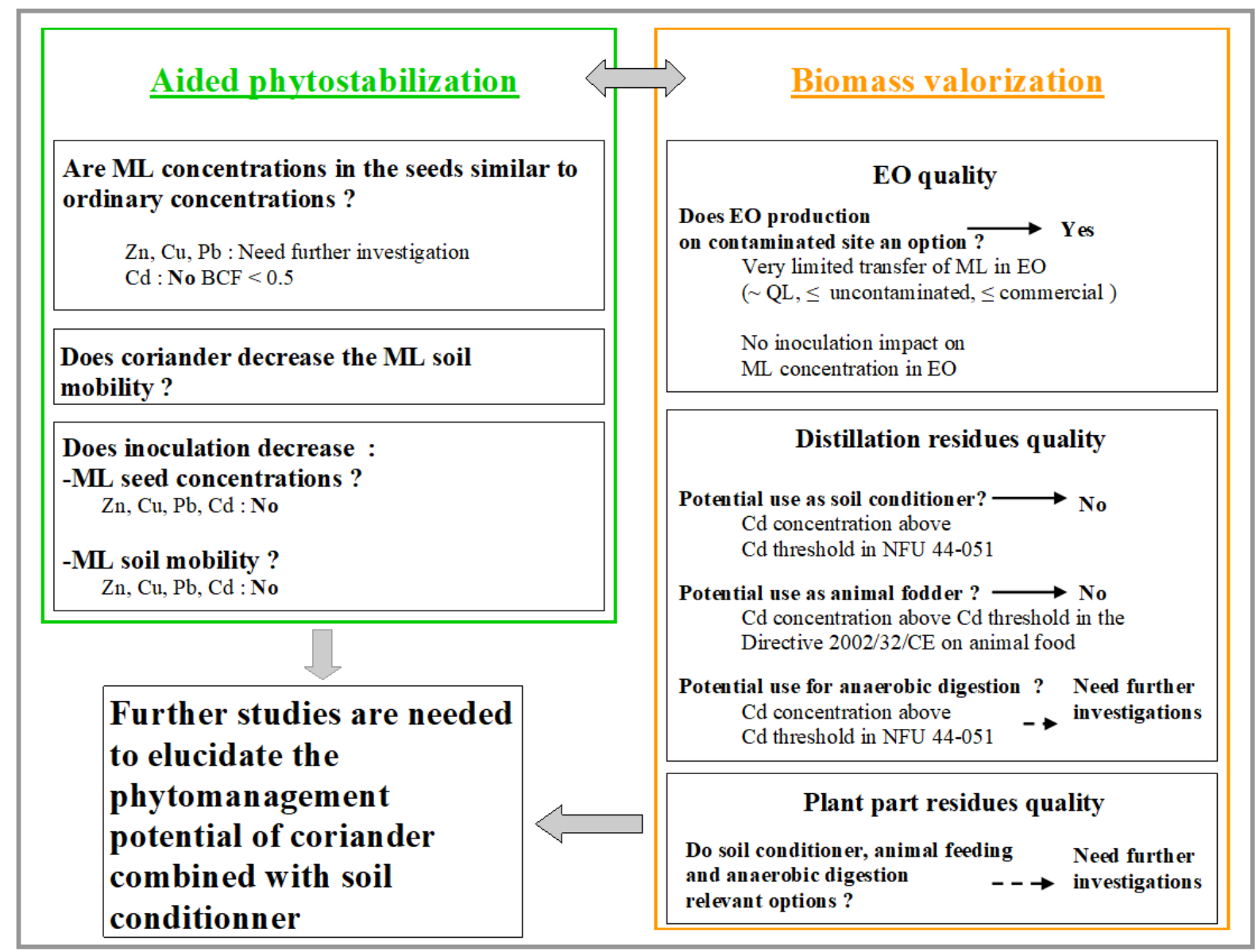


Supplemental Table 1. TE recovery values obtained by ICP-OES and MS in the soil, water and plant certified reference materials. Information in brackets refer to paragraph in the text.

\section{Reference} materials

As

Cd

$\mathrm{Cr}$

$\mathrm{Cu}$

Ni

Pb

Sb

Zn

\begin{tabular}{|c|c|c|c|c|c|c|c|c|}
\hline $\begin{array}{l}\text { Soil } \\
(\$ 2.2) *\end{array}$ & [0.91-0.97] & [0.91-1.13] & [0.94-1] & [0.86-0.99] & [1.21-1.31] & [0.89-1.04] & [0.77-0.9] & [0.85-1.08] \\
\hline $\begin{array}{l}\text { Plant } \\
(\$ 2.3 ; \S 2.5)^{+}\end{array}$ & 0.86 & [0.71-0.99] & - & [0.88-0.92] & [0.77-1.03] & - & [0.84-1.04] & [0.96-1.14] \\
\hline $\begin{array}{l}\text { Water } \\
(\$ 2.4)^{++}\end{array}$ & 0.9 & 1.07 & 0.96 & 0.94 & 0.95 & 0.98 & 0.88 & 0.86 \\
\hline
\end{tabular}

* NIST SRM 2710, Montana soil.

+ White cabbage «BCR $679 »$, JRC, community bureau of reference, http://www.irmm.jrc.be/mrm.html. No recovery values were available for $\mathrm{Cr}$ and $\mathrm{Pb}$.

++ Environmental matrix water «TMDA - 62.2», Environnent Canada. 
Supplemental Table 2. Percent of mobile TE (As, Cd, Cr, $\mathrm{Cu}, \mathrm{Ni}, \mathrm{Pb}, \mathrm{Sb}$, and $\mathrm{Zn}$ ) calculated as extractable concentrations over total concentrations) in soil with inoculated (I) and non-inoculated (NI) coriander, before harvest of shootsand seeds, and sage, before harvest of leaves (year 1) and inflorescences (year 2) (mean \pm SD). Significant differences between conditions (I, NI, year 1 and year 2) are indicated by the different letters in bold at the level of $\alpha=0.05$. Percent of mobile TE in the contaminated soil before the set up of the experiment, i.e. initial state, is also shown (mean $\pm \mathrm{SD}$ ).

\begin{tabular}{|c|c|c|c|c|c|c|c|c|}
\hline Initial State & As & Cd & $\mathrm{Cr}$ & $\mathbf{C u}$ & $\mathrm{Ni}$ & $\mathbf{P b}$ & $\mathbf{S b}$ & $\mathbf{Z n}$ \\
\hline Contaminated & $0.06(0.02)$ & $1.63(0.51)$ & $0.02(0.02)$ & $1.08(0.41)$ & $0.2(0.04)$ & $0.02(0.006)$ & $0.97(0.28)$ & $0.21(0.07)$ \\
\hline Coriander & As & Cd & $\mathrm{Cr}$ & $\mathbf{C u}$ & $\mathbf{N i}$ & $\mathbf{P b}$ & $\mathbf{S b}$ & $\mathbf{Z n}$ \\
\hline \multirow{2}{*}{ Shoots NI } & 0.06 & 1.9 & 0.01 & 1.04 & 0.17 & 0.02 & 1.03 & 0.66 \\
\hline & $(0.014)$ & $(0.74)^{\mathbf{a}}$ & $(0.001)^{\mathrm{a}}$ & $(0.48)$ & $(0.04)$ & $(0.009)$ & $(0.28)^{\mathbf{a}}$ & $(0.32)^{\mathbf{a}}$ \\
\hline \multirow{2}{*}{ Shoots I } & 0.05 & 1.63 & 0.01 & 1.98 & 0.18 & 0.016 & 1.21 & 0.56 \\
\hline & $(0.014)$ & $(0.55)^{\mathrm{a}}$ & $(0)^{\mathbf{a}}$ & $(2.22)$ & $(0.06)$ & $(0.003)$ & $(0.22)^{\mathbf{a . b}}$ & $(0.24)^{\mathrm{a}}$ \\
\hline \multirow[b]{2}{*}{ Seed NI } & 0.069 & 2.27 & 0.014 & 2.02 & 0.28 & 0.03 & 0.876 & 0.27 \\
\hline & $(0.03)$ & $(0.97)^{\mathbf{b}}$ & $(0.003)^{\mathbf{b}}$ & $(1.8)$ & $(0.07)$ & $(0.019)$ & $(0.26)^{\mathbf{b}}$ & $(0.19)^{\mathbf{b}}$ \\
\hline \multirow{2}{*}{ Seed I } & 0.053 & 1.84 & 0.011 & 1.18 & 0.22 & 0.02 & 0.921 & 0.16 \\
\hline & $(0.015)$ & $(0.42)^{\mathbf{a}}$ & $(0.001)^{\mathbf{a}}$ & $(0.26)$ & $(0.03)$ & $(0.006)$ & $(0.15)^{\mathbf{a . b}}$ & $(0.04)^{\mathbf{b}}$ \\
\hline \multirow[t]{2}{*}{ Sage } & As & Cd & $\mathrm{Cr}$ & $\mathrm{Cu}$ & $\mathbf{N i}$ & $\mathbf{P b}$ & Sb & $\mathbf{Z n}$ \\
\hline & 0.049 & 2.07 & 0.011 & 2.31 & 0.17 & 0.02 & 1.25 & 0.65 \\
\hline \multirow[t]{2}{*}{ Leaves NI } & $(0.014)^{\mathbf{A}}$ & $(0.7)^{\mathbf{A . B}}$ & $(0.001)^{\mathbf{A}}$ & $(2.54)$ & $(0.06)^{\mathbf{A}}$ & $(0.009)^{\mathbf{A}}$ & $(0.19)^{\mathbf{A}}$ & $(0.39)^{\mathbf{B}}$ \\
\hline & 0.09 & 1.78 & 0.011 & 1.36 & 0.15 & 0.013 & 1.59 & 0.44 \\
\hline Leaves I & $(0.05)^{\mathbf{B}}$ & $(0.28)^{\mathbf{A}}$ & $(0)^{\mathbf{A . B}}$ & $(0.2) 3$ & $(0.03)^{\mathbf{A}}$ & $(0.002)^{\mathbf{A}}$ & $(0.27)^{\mathbf{B}}$ & $(0.27)^{\mathbf{A . B}}$ \\
\hline Inflorescences & 0.04 & 2.37 & 0.014 & 0.93 & 0.29 & 0.03 & 0.72 & 0.26 \\
\hline NI & $(0.01)^{\mathbf{A}}$ & $(0.46)^{\mathbf{B}}$ & $(0.004)^{\mathbf{B}}$ & (1.11) & $(0.16)^{\mathbf{B}}$ & $(0.012)^{\mathbf{A}}$ & $(0.18)^{\mathbf{C}}$ & $(0.113)^{\mathbf{A}}$ \\
\hline Inflorescences & 0.1 & 2.08 & 0.02 & 1.31 & 0.27 & 0.07 & 0.93 & 0.25 \\
\hline $\mathbf{I}$ & $(0.04)^{\mathbf{B}}$ & $(0.32)^{\mathbf{A . B}}$ & $(0.006)^{\mathrm{C}}$ & $(2.25)$ & $(0.05)^{\mathbf{B}}$ & $(0.04)^{\mathbf{B}}$ & $(0.19)^{\mathbf{D}}$ & $(0.17)^{\mathbf{A}}$ \\
\hline
\end{tabular}

